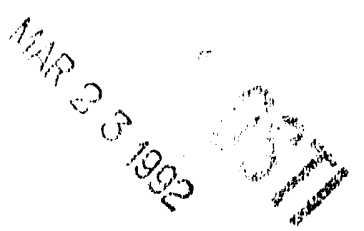

\title{
USE OF THE EDMONDS-REILLY MODEL TO MODEL ENERGY-RELATED GREENHOUSE GAS EMISSIONS
}

\author{
D. W. Barns \\ J. A. Edmonds \\ J. M. Reillyn
}

January 1992

Prepared for

the U.S. Department of Energy

under Contract DE-AC06-76RLO 1830

\section{Pacific Northwest Laboratories \\ Richland, Washington 99352}

\section{DISCLAIMER}

This report was prepared as an account of work sponsored by an agency of the United States Government. Neither the United States Government nor any agency thereof, nor any of their employees, makes any warranty, express or implied, or assumes any legal liability or responsibility for the accuracy, completeness, or usefulness of any information, apparatus, product, or process disclosed, or represents that its use would not infringe privately owned rights. Reference herein to any specific commercial product, process, or service by trade name, trademark, manufacturer, or otherwise does not necessarily constitute or imply its endorsement, recommendation, or favoring by the United States Government or any agency thereof. The views and oninions of authors expressed herein do not necessarily state or reflect those of the United States Government or any agency thereof. 


\section{SUMMARY}

At the request of the General Economics Brarich of the Organization for Economic Cooperation and Development (OECD), the Edmonds-Reilly Model was modifled and run iteratively against several standardized scenarios for comparison with results of other models in order to provide a basis for the assessment of costs of reducing $\mathrm{CO}_{2}$ emissions. This paper describes the model modifications required, as well as the results of the various modeling runs. 


\section{GREENHOUSE GAS EMISSIONS}

\section{INTRODUCTION}

The purpose of this paper is to document the results of our application of the Edmonds-Reilly Model (ERM) using several scenarios provided for an Organization for Economic Cooperation and Development (OECD) project comparing global models. Because the output of this exercise is data-rich, most of this exposition is in graphical form, with the narrative serving mainly as a roadmap for moving from one highlight to the next. The first two sections of the paper briefly describe the model and some of the special modifications made for this effort. The case-by-case discussion is contained in Section IV, followed by a summary of the potential pitfalls involved in attempting to assess the cost of emissions reduction from the model data.

\section{MODEL DESCRIPTION}

For this exercise we have used a specially modified version of the ERM. The ERM is a well documented, frequently used, long-term model of global energy and fossil fuel greenhouse gas emissions. The model consists of four modules: supply, demand, energy balance, and greenhouse gas emissions. The first iwo modules determine the supply of and demand for each of six major primary energy categories in each of nine global regions. The energy balance module ensures model equilibrium in each global fuel market. (Primary electricity is assumed to be untraded; thus supply and demand balance in each region.) The greenhouse gas emissions module is a set of three post-processors which calculate the energy-related emissions of $\mathrm{CO}_{2}, \mathrm{CH}_{4}$, and $\mathrm{N}_{2} \mathrm{O}$. The original version of the model is documented in Edmonds and Reilly (1985), while major revisions are discussed in Edmonds et al. (1986).

Energy demand for each of the six major fuel types is developed for each of the nine regions. Five major exogenous inputs determine energy demand: population; labor productivity; exogenous energy end-use intensity; energy prices; and energy taxes, subsidies, and tariffs.

The model calculates base gross national product (GNP) directly as a product of labor force and labor productivity. An estimate of base GNP for each region is used both as a proxy for the overall level of economic activity and as an index of income. The base GNP is, in turn, modified within the model to be consistent with energy-economy interactions. Each region has its own GNP feedback elasticity, allowing the model to distinguish energy supply dominant regions where energy prices and GNP are positively related, from the rest of the world where the relationship is inverse. For example, a substantial rise in world oil prices would tend to enhance the GNP in the Mideast, while reducing GNP in other regions.

The exogenous end-use energy-intensity improvement parameter is a time-dependent index of energy productivity. It measures the annual rate of growth of energy productivity which would continue independent of such other factors as energy prices and real income changes. In the past, technologicir progress and other non-price factors have had an important influence on energy use in the manufacturing sector of advanced economies. By including an exogenous end-use energy-intensity improvement parameter, scenarios can be developed that incorporate either continued improvements or technological stagnation assumptions as an integral part of scenarios. 
The final major el.eigy factor influencing demand is energy prices. Each region has a unique set of energy prices derived from world prices (determined in the energy balance component of the model) and region-specific taxes and tariffs. The model can be modified to accommodate non-trading regions for any fuel or set of fuels. It is assumed that no trade is carried on between regions in solar, nuclear, or hydroelectric power, but all regions trade fossil fuels.

The energy-demand module performs two functions: 1) it establishes the demand for energy and its services, and 2) it maintains a set of energy flow accounts of each region. Oil and gas are transformed into secondary liquids and gases used either directly in end-use sectors or indirectly as electricity. Hydro, nuclear, and solar electric or fusion are accounted for directly as electricity. Non-electric solar energy is included with conservation technologies as a reduction in the demand for marketed fuels. The four secondary fuels are consumed to produce energy senvices.

The demand for energy services in each region's end-use sector(s) is determined by the cost of providing these services and by the levels of income and population. The mix of secondary fuels used to provide these services is determined by the relative costs of providing these services using each alternative fuel. The demand of fuels to provide electric power is then determined by the relative costs of production, as is the share of oil and gas transformed from coal and biomass.

Energy supply is disaggregated into two categories, renewable and non-renewable. Energy supply from all fossil fuels is related directly to the resource base by grade, to the cost of production (both tochnical and environmental), and the historical production capacity. The introduction of a graded resource base for fossil fuel (and nuclear) supply allows the model to explicitly test the importance of fossil fuel resource constraints as well as to represent fuels such as shale oil, where only small amounts are likely to be available at low cost, but for which large amounts are potentially available at high cost.

Note here that nuclear is treated in the same categiory as fossil fuels. Nuclear power is constrained by a resource base as long as light-water reacto's are the dominant producers of power. Breeder reactors, by producing more fuel than they consume, are modeled as an essentially unlimited source of fuel that is available at higher cost.

A rate of technological change is also introduced on the supply side. This rate varies by fuel and is expected to be both higher and less certain for emerging technologies.

The supply and demand modules each generate energy supply and demand estimates based on exogenous input assumptions and energy prices. If energy supply and demand match when summed across all trading regions in each group for each fuel, then the global energy system balances. Such a result is unlikely at an arbitrary set of energy prices. The energy balance component of the model is a set of rules for choosing energy prices which, on successive attempts, bring supply and demand nearer to system-wide balance. Successive energy price vectors are chosen until energy markets balance within a prespecified bound.

Given the solution of the energy balance component of the model, greenhouse gas emissions for $\mathrm{CO}_{2}, \mathrm{CH}_{4}$ and $\mathrm{N}_{2} \mathrm{O}$ are calculated by applying emissions coefficients to the different fuels. Emissions coefficients for $\mathrm{CO}_{2}$

(given in carbon weight emissions) are as follows:

- liquids

- gases

- solids

- carbonate rock mining
19.9 TgC/EJ

13.7 TgC/EJ

24.1 TgC/EJ

$27.9 \mathrm{TgC} / \mathrm{EJ}$ 
Modern biomass is treated as if its carbon absorption occurred in the year of release. This approximation can either under- or over-estimate actual net annual fluxes depending upon whether the underlying stock of blomass is either expanding or contracting.

\section{MODEL MODIFICATIONS}

To promote a common approach, certain standardized input assumptions were provided which required some significant modifications to the model. The first of these had to do with time periods for reporting results. It was desired that reporting commence in 1990, with results given every 5 years through 2010, and then every 10 years through 2100. The standard version of ERM starts in 1975, and uses 25-year intervals through 2100. As a compromise approach, it was decided to change the ERM periodicity to 15 years, commencing in 1975, and to modify parameters as necessary to conform to the specified energy consumption data for 1990. These c ata were based on OECD energy balances. In the recalibration, the number of end-use consumption seciors for developing countries was expanded from one to three. Primary energy prices to clear 1990 markets were production-weighted averages of prices for the previous 15 years. ${ }^{(a)}$

Geographical regions for reporting purposes were to be: (1) the U.S., (2) Other OECD, (3) USSR, (4) China, and (5) the rest of the world (ROW). The ERM provides results for nine regions which were telescoped to five for reporting purposes, except that it should be noted that the ERM groups USSR with Eastern Europe nations and China with other Asian centrally-planned economies. The result is that totals reported herein are inflated by roughly half for the USSR, with a corresponding reduction to the ROW totals; whereas, the effect on China totals is virtually insignificartt.

Key assumptions on economic growth, population growth, and the oil and gas resource base were specified for the OECD's exercise to be the same as those laid down for the Energy Modeling Forum's parallel exercise(referred to hereafter as EMF-12). Economic growth was specified in terms of 1990 regional GDP totals along with growth rates to be applied. For this effort, GDP was used interchangeably with GNP. Population projections specified had previously been incorporated in the model and no change was required. Oil and natural gas resource base assumptions were incorporated resulting in somewhat less oil and somewhat more gas than had previously been provided in the ERM.

The goal of the modifications was to have the model's 1990 projections coincide as nearly as possible with energy data derived from OECD Energy balances. The specific target was secondary

(a) The use of average prices for the 15 years prior to 1990 is necessary to reflect the fact that energy demands in the year 1990 reflect both 1990 prices and the much highier prices that existed prior to that date. In fact, throughout the prior 15 years energy prices were higher than in 1990, with the peak in world oil prices oocurring in 1981. 
energy both by source and by consuming sector. The result is shown below:

Variable

Primary Energy

Oil

Gas

Coal

Biomass

Hydro

Other

Total

Secondary Energy

Liquids

Solids

Gases

Electric

Heat

Total

Final Consumption

Industry

Transport

Residential/Cominercial

Other

Total

Carbon Emissions
EMF-12 Target

134.18

72.89

96.43

0.00

22.20

18.86

344.56

112.23

42.28

43.98

36.04

$\frac{7.97}{2.50}$

2.42 .50

102.78

61.61

58.42

15.05

237.86

6003
ERM Result

136.66

71.56

94.36

4.02

23.90

21.73

352.23

113.83

42.77

42.07

44.21

0.00

242.88

124.77

59.88

58.24

$\underline{0.00}$

242.89

5767

Note that the ERM has no provision for handling "Heat", so that quantity was combined with electricity. Also, the final consumption category listed as "Other" was reassigned, mainly to the industrial sector.

\section{DISCUSSION OF RESULTS}

As a vehicle to explore greenhouse emissions control strategies, a reference case was modeled, along with five tax scenarios. In addition, selected parameters were varied in order to examine their impact on model results. These cases are discussed in the following sections in the order given, starting with the reference case.

Case 0-Business as Usual (Table 1). This is simply the baseline run with no control measures applied. Figure 1 shows the resulting primary energy consumption by source. It will be seen that oil consumption is essentially level through the first third of the next century, then diminishes gradually, approaching depletion near the end of the century. Natural gas use nearly triples, then falls off sharply, approaching depletion by the end of the century. Coal progressively dominates the economy accounting for $63 \%$ of primary energy consumption in the final period. The share of nuclear and renewable sources rises steadily, approaching a third of the total. What is not apparent in the figure is that an increasing share of solids is converted to synthetic fuels, approaching $60 \%$ of the total by 2095 , corresponding to $313 \mathrm{Ej}$ of synoil and $58 \mathrm{Ej}$ of syngas at that point. Figure 2 shows this same primary energy total by consuming 
region. Here the developed regions show only modest growth while the developing regions exhibit dramatic growth, their share increasing from $24 \%$ in 1990 to $63 \%$ in 2095.

Figure 3 displays the consumption of secondary energy by source, showing a nearly five-fold growth in electricity, reflecting not only market preference but also the increase in nuclear, solar, and hydro sources. Solids and liquids both grow significantly, while gases drop off as the period closes. One must recall that the majority of liquids and gases are from synthetic origin by this time. Figure 4 shows secondary consumption by sector--industrial, transportation, and residential/commercial--each one growing by a factor of about $2-1 / 2$ to 3 times.

Carbon emissions from the combustion of fossil fuel are shown in Figure 5 which closely parallels regional primary consumption as shown in Figure 2, expanding almost 4 times in the period of interest.

Case 1.1\% Per Annum Reduction in the Rate of Growth of Emissions (Table 2). In this scenario the intention is to apply carbon taxes as necessary to force all regions to reduce the rate of growth of carbon emissions by $1 \%$ per year. This was interpreted as requiring the calculation for each region, from the business-as-usual case, an average annual growth rate for each 15-year period. From the average annual rate, one percentage point was subtracted, resulting in negative growth in many cases. These revised gruwth rates were then recompounded for each region and each 15-year period to derive the allowable emissions as shown in Figure 6. The effect on individual regions, because it hinges on the unconstrained trajectory, is obviously different among the regions. Global totals are allowed to rise by $38 \%$ over 1990 levels by 2095 ; but the U.S. must reduce by $28 \%$, while China is permitted to grow by a factor of almost five. The impact on primary energy consumption is shown in Figure 7, with coal substantially constricted, growing only as it becomes a source for synfuels, with $66 \%$ converted by 2095 . Gas use is similarly diminished, thereby forestalling depletion within the time under consideration. Although oil appears to be nearly depleted, augmentation from synoil results in only a $36 \%$ reduction in consumption because of the relatively inflexible demand for transportation. Nuclear and renewable consumption increases to two-thirds of the total.

Tax rates imposed to effect this reduction are given in Table 2. For a variety of reasons, the U.S. is more expensive to control. These reasons include the relatively high-demand share of energy for transportation and the proportion of coal initially used in the overall total. Conversely, the USSR, is in most cases, least impacted because of the relatively lower demand growth for coal built into the assumptions. Model calculations of reduction in GNP are also shown in Table 2. A fuller discussion of costs of emissions reductions is found in Section $\mathrm{V}$.

Case 11-2\% Per Annum Reduction in the Rate of Growth of Emissions (Table 3). As seen in Figure 8, this scenario requires that emissions by the end of the next century be reduced to exactly half of 1990 levels. Primary energy (see Figure 9) is reduced to $63 \%$ of the business-as-usual case, of which $85 \%$ is from nuclear and renewable sources. Coal consumption is cut in half before mid-century, but later returns to nearly 1990 levels, of which three-quarters are used for synoil production. The required tax rates serve virtually to eliminate the use of fossil fuel in the U.S., except for about $10 \mathrm{Ej}$ of oil, most of which is of synthetic origin.

Case 111-3\% Per Annum Reduction in the Rate of Growth of Emissions (Table 4). This is an extreme constraint resulting in reducing emissions to less than $20 \%$ of 1990 levels by 2095 (see Figure 10). For the ERM, as presently configured, this is on the threshold of insolubility, so the results are considered approximate. From Figure 11 we note that primary energy is cut nearly in half from the unconstrained case, and of that total, $92 \%$ comes from nuclear and renewable sources. From the tax rate table, it is obvious by using this approach to emissions reduction quotas, that the U.S. continues to be the most 
severely disadvantaged, with a tax in later years of an order of magnitude of $\$ 10.00$ per gallon on gasoline.

Case IV-Stabilization of Emissions at 1990 Levels (Table 5). In this case, total energy consumption is reduced to $65 \%$ of the unconstrained case. Primary energy shares are similar to those previously shown, except that nuclear and renewables ultimately assume only $69 \%$ of the total by the final period (see Figure 12). Comparing the tax rates with the previous two cases shows that it is relatively much easier for the U.S. to stabilize than to reduce emissions. Also, note the relative difference in taxes between the developed and the developing countries, where the latter are now pe,rmitted no growth. The effect on GNP is reflected in Table 5, where it is seen that developing countries bear most of the burden.

Case V-Emissions Trading (Table 6). This scenario calls for reducing growth in carbon emissions by $2 \%$ per year through some scheme of trading emissions permits. First, the marginal cost must be known to provide the basis for a sell or buy decision. This is given by the discrete tax rate which must be imposed on each region to force the required reduction; viz., the Case II rates which are shown in Figure 13. Next, in order to establish the price of emissions perrnits, a uniform global tax was imposed to achieve the aggregate reduction equivalent to the Case II total. These tax rates are overlaid in Figure 13 as the permit price line. Presumably, those regions whose marginal cost of emissions reduction is less than the permit price could reduce emissions further by other unspecified, but lower cost means (i.e., less than the permit price), and sell emissions permits at the trading price to regions whose marginal cost is higher than the trading price. Resulting emissions would tend to approach those shown in Figure 14 in the limit. For comparison purposes, the right-hand column from Figure 8 has been brought forward to show the difference in terminal regional emissions between the trading and non-trading case. Here it is seen that the USSR and China have sold trading permits to the other regions while reducing their own emissions to maintain the same total.

Sensitivity to Selected Parameters. The purpose of this set of runs was to examine the effect on emissions of variations in the autonomous end-use efficiency improvement (AEEI) and elasticity of substitution parameters.

AEEl. In the ERM, energy-use efficiency improvement is taken up in one model variable, TKL, which is the annual rate of improvement. Previous sensitivity studles with the model have shown this to be one of the most powerful of the parameters affecting demand. It is compounded over the time interval of iteration and serves to reduce the demand for secondary energy. It is normally set at $1 \%$ in the ERM. For this study, the value was also set at $0 \%$ and $0.5 \%$. Figures 15 and 16 show the resulting effect on primary energy demand from these two values compared with the reference value of $1 \%$. With no efficiency improvement demand nearly triples by 2095, resulting in exhausting conventional oil and gas resources. For the mid-range value, demand is increased over the reference case by about $60 \%$ by the end of the period. Figure 17 shows the resulting emissions, which are similar to the fossil fuel envelope of the demand curves, but which are increasing at a greater rate because of the progressively increasing share of coal.

Tax rates used to effect the $2 \%$ growth reduction from Case II were imposed to show the sensitivity of a tax case to changes in parameters. Results are shown in Figure 17, where it is seen that the lower values of $T K L$ result in correspondingly less reductions in emissions.

Elasticity of Substitution. End-use elasticity in the ERM is controlled by the variable RPJ which is normally set at $-3,0$. For this study, the value was varied between -1.5 and -6.0 , with the effects on primary energy consumption shown in Figures 18 and 19. With the higher (more negative) value, the bias towards least cost is increased, resulting in greater direct use of fuels rather than conversion to synfuels 
and electricity. In this case for the final period, $1233 \mathrm{Ej}$ of primary energy is consumed as $856 \mathrm{Ej}$ of secondary energy (of which $103 \mathrm{El}$ is electrical), with the balance of 377 being lost in conversion to electricity and synfuels. For the lower value of elasticity, $1389 \mathrm{Ej}$ of primary energy provides $646 \mathrm{Ej}$ of secondary energy (of which 222 Ej is electrical) with the balance of 743 Ej being lost in conversion. Carbon emissions for both cases are as shown in Figure 20. The low elasticity case is somewhat higher for most of the time, because although the total amount of fossil fuel is nearly the same in both cases, the relative shares of the three fuels change over time. Imposing Case $\|$ tax rates results in very little difference in response until the !ast two periods. At this point, the preference for lower costs imposed by the high elasticity forces the fuel consumption profile away from end-use consumption of fossil fuels towards non-emitting sources in the form of electricity.

Elasticity of substitution for electric utilities is controlled by the variable RUI which is norrially set at 3.0. Runs were made setting this variable to -1.5 and -6.0 , giving primary energy profiles as shown in Figures 21 and 22. In both cases, secondary energy is nearly equal. For the higher elasticity case, utilities have a greater preference for lower cost and consistently use more coal (more than double the low elasticity case). As a result, electricity costs less, and it constitutes a somewhat larger share of secondary energy so primary energy use must increase to offset the greater conversion losses. This is seen in Figure 22 where consumption slightly exceeds the reference case. In Figure 21, on the other hand, low elasticity causes primary consumption to be less than the reference case. From Figure 23 , it is seen that emissions for the high elasticity case consistently exceed the low case by about $5 \%$ to $10 \%$ because of the greater use of the lower cost coal. Response to Case II tax rates is significant for the higher elasticity vis-a-vis the low for the same reason as the end-use case.

\section{COST OF EMISSIONS REDUCTION}

The total cost of emissions reduction has not heretofore been discussed in this paper. The reporting instructions call for GNP reductions resulting from the various tax cases, and these have been provided in the tables and figures. However, we feel that where major restrictions are imposed the ERM-calculated GNP reduction is probably not a true measure of the economic scarcity costs involved. In Edmonds and Barns (1990), which was also based on ERM modeling results, we concluded that simply examining the change in GNP was unlikely to provide a useful measure of the total cost of emissions reductions. The reason for this is that the change in GNP is determined by the change in the cost of energy services and a single elasticity parameter. This value of the GNP feedback elasticity is, in general, small. It is therefore not a matter of great concern in determining the total rate of carbon emissions or energy production and consumption. A more sensitive gauge is needed to measure cost. In Edmonds and Barns (1990), we measured cost as the integral of the marginal cost schedule derived by systematically varying the tax rate. The difference between developing the total cost of emissions reductions which can be shown to be equal to the loss in GNP under appropriate conditions, is significant. Economic losses based on a GNP elasticity are as much as a factor of four greater than costs derived as an integral over marginal cost.

Using the ERM as presently configured, running with increasing tax rates applied $i$. the marginal cost curves shown in Figure 24. Integration using a simple trapezoidal rule method gives total costs shown in Figure 25. Shown in terms of percent reduction, the total costs become closely grouped and nearly linear as seen in Figure 26. By contrast, the GNP reduction calculated by the ERM for this same set of runs looks like Figure 27. It is seen that for the year 2005 the GNP loss and the total costs are about the same, but in later periods, the GNP loss grows compared to the total costs until in the last period it is larger by four-fold. As an experiment, the same set of runs was repeated with the value of the GNP feedback elasticity cut by a factor of four which yielded GNP losses as shown in Figure 28. Here, the latest year line is close to the total cost, but the earliest is low by a factor of four. It would be tempting but not intellectually satisfying to pick some middle value of feedback elasticity which would 
minimize the apparent distortions. We feel a much better appr Jach would be to compute total costs for each scenario; however, this requires several iterations per scenario which is beyond the scope of this effort. For the present, we can only say that for extreme conditions, the GNP reduction figures reported by the model likely overstate the cost of emissions reduction by a significant amount. 


\section{REFERENCES}

Edmonds, J.A. and D.W. Barns 1990. Estimating the Marginal Cost of Reducing Global Fossil Fuel $\mathrm{CO}_{2}$ Emissions. PNL-SA-18361, Pacific Northwest Laboratory, Washington, D.C.

Edmonds, J.A. and J.M. Reilly 1985. Global Energy: Assessing the Future. Oxford University Press, New York.

Edmonds, J.A., J.M. Rellly, R.H. Gardner, and A. Brenkert 1986. Uncertainty in Future Global Energy Use and Fossil Fuel $\mathrm{CO}_{2}$ Emissions 1975 to 2075. TR036, DO3/NBB-0081 Dist. Category UC-11, National Technical Information Service, U.S. Department of Commerce, Springfield, Virginia. 

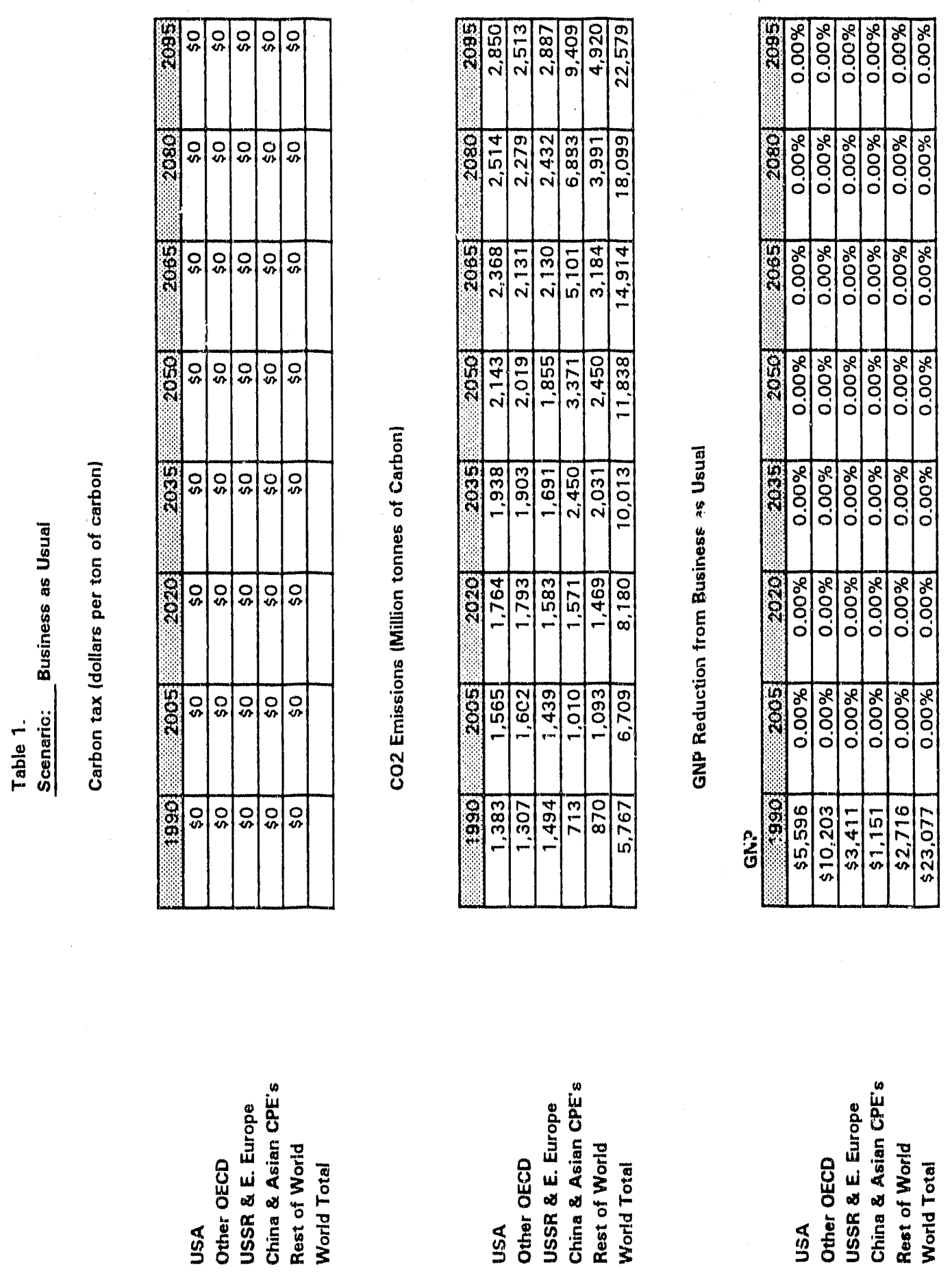

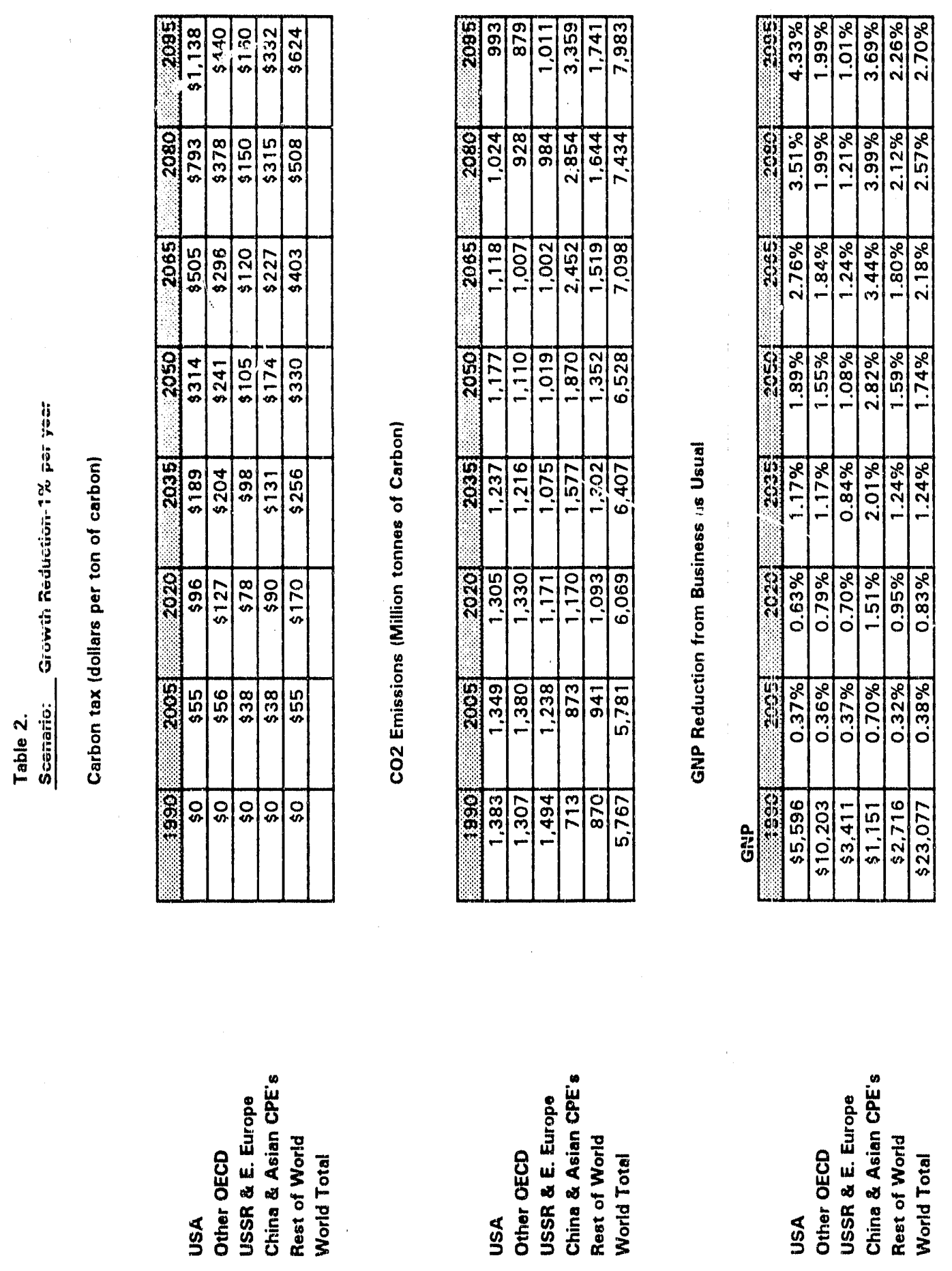

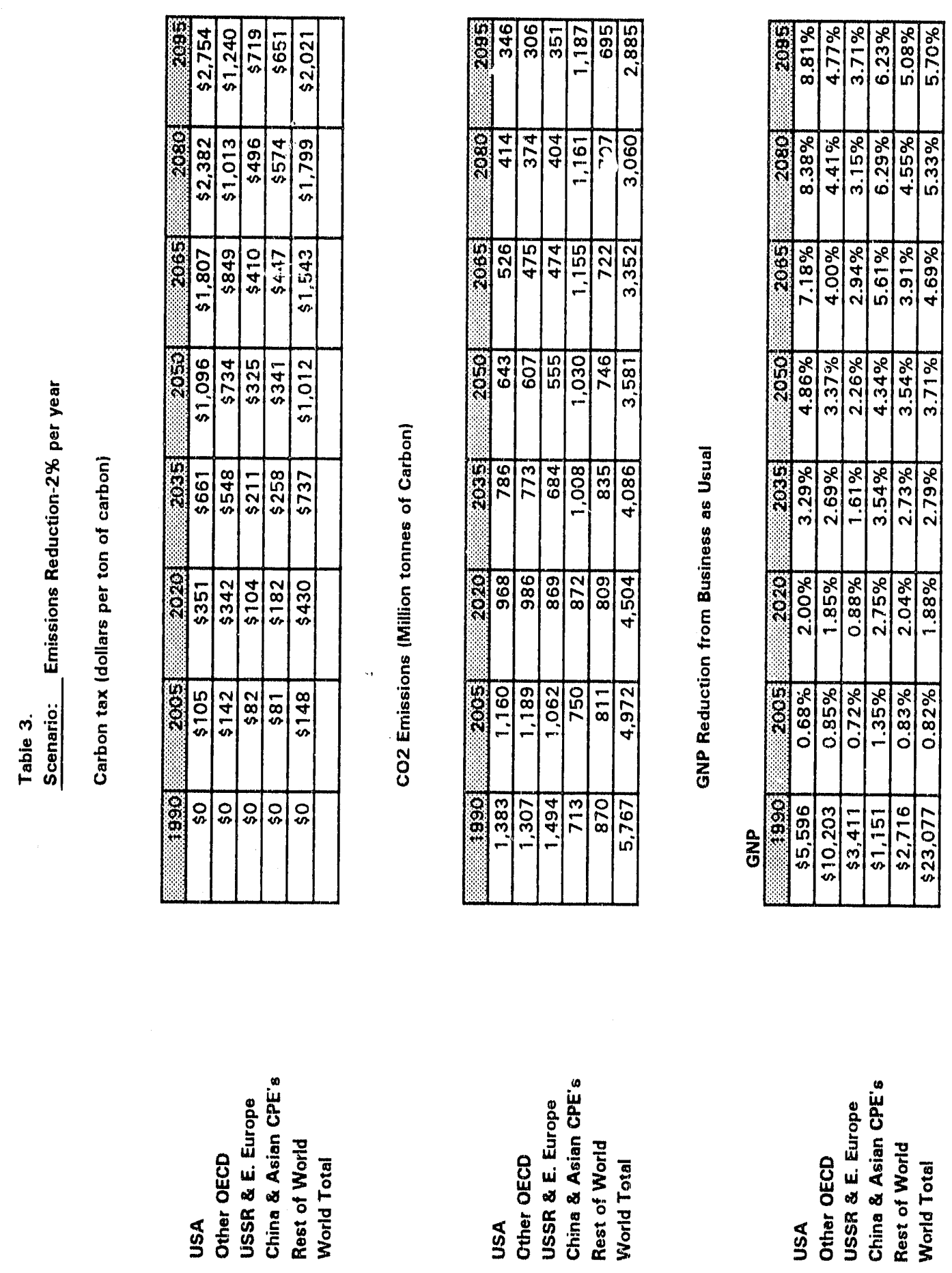

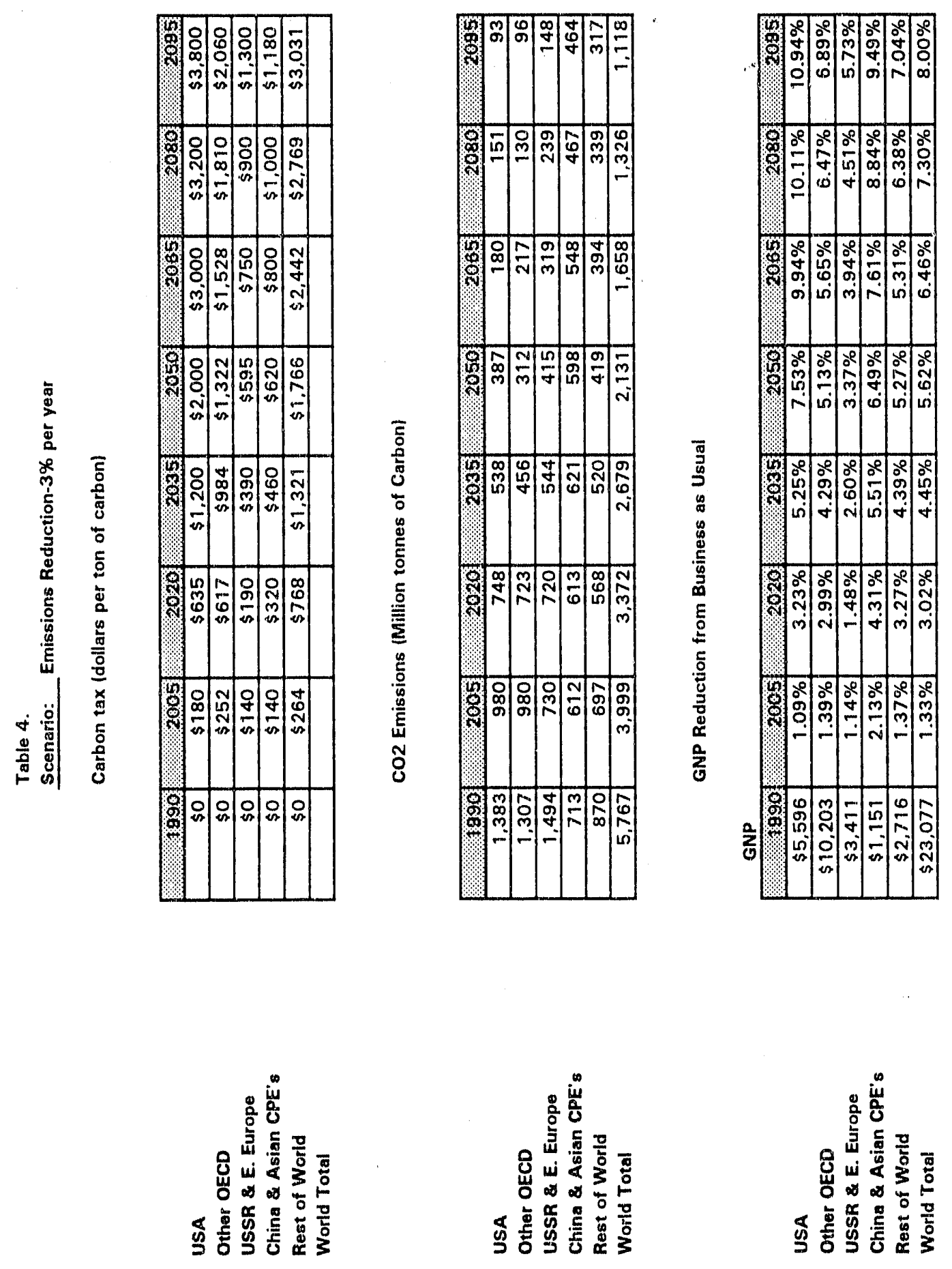

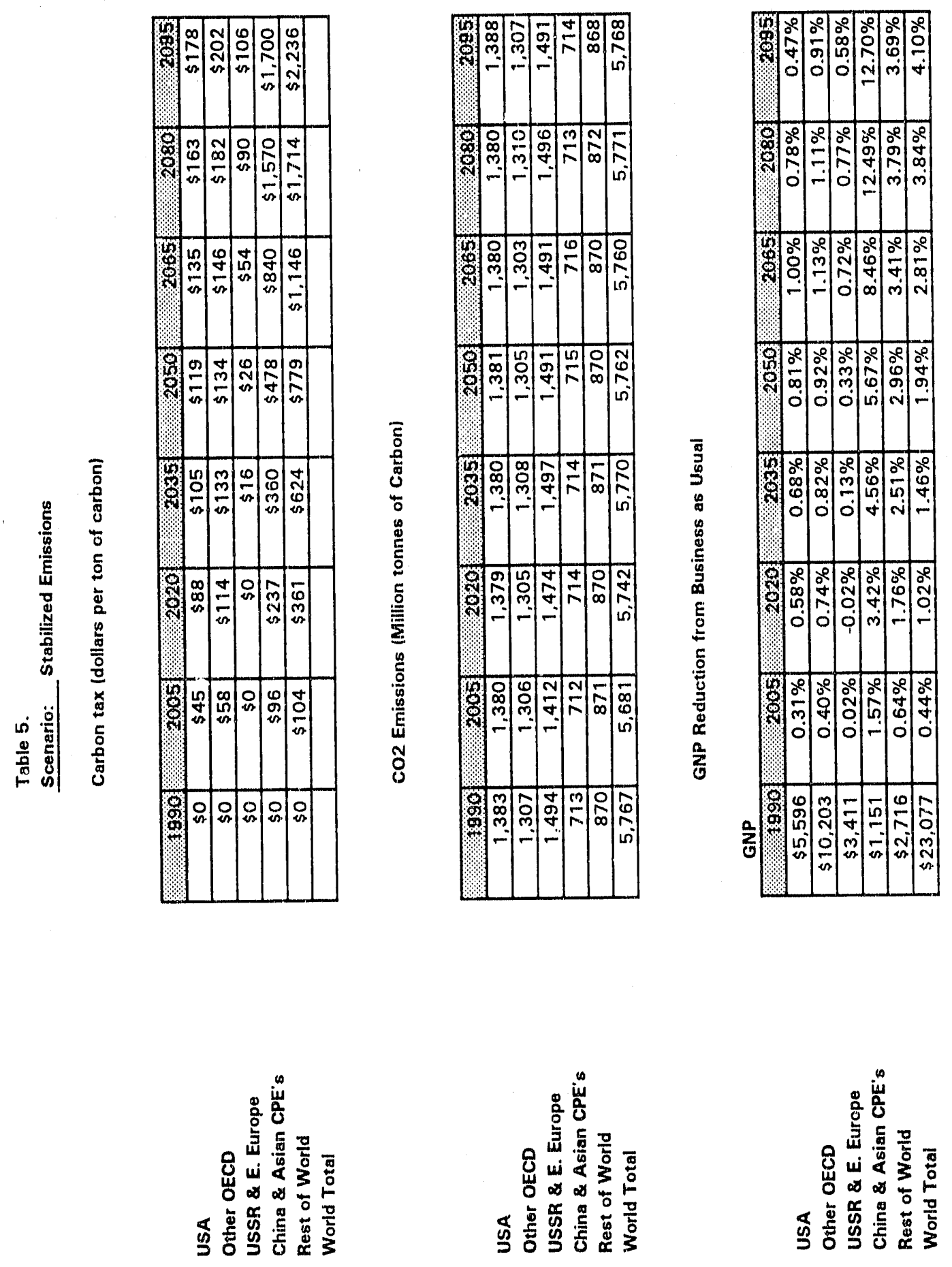

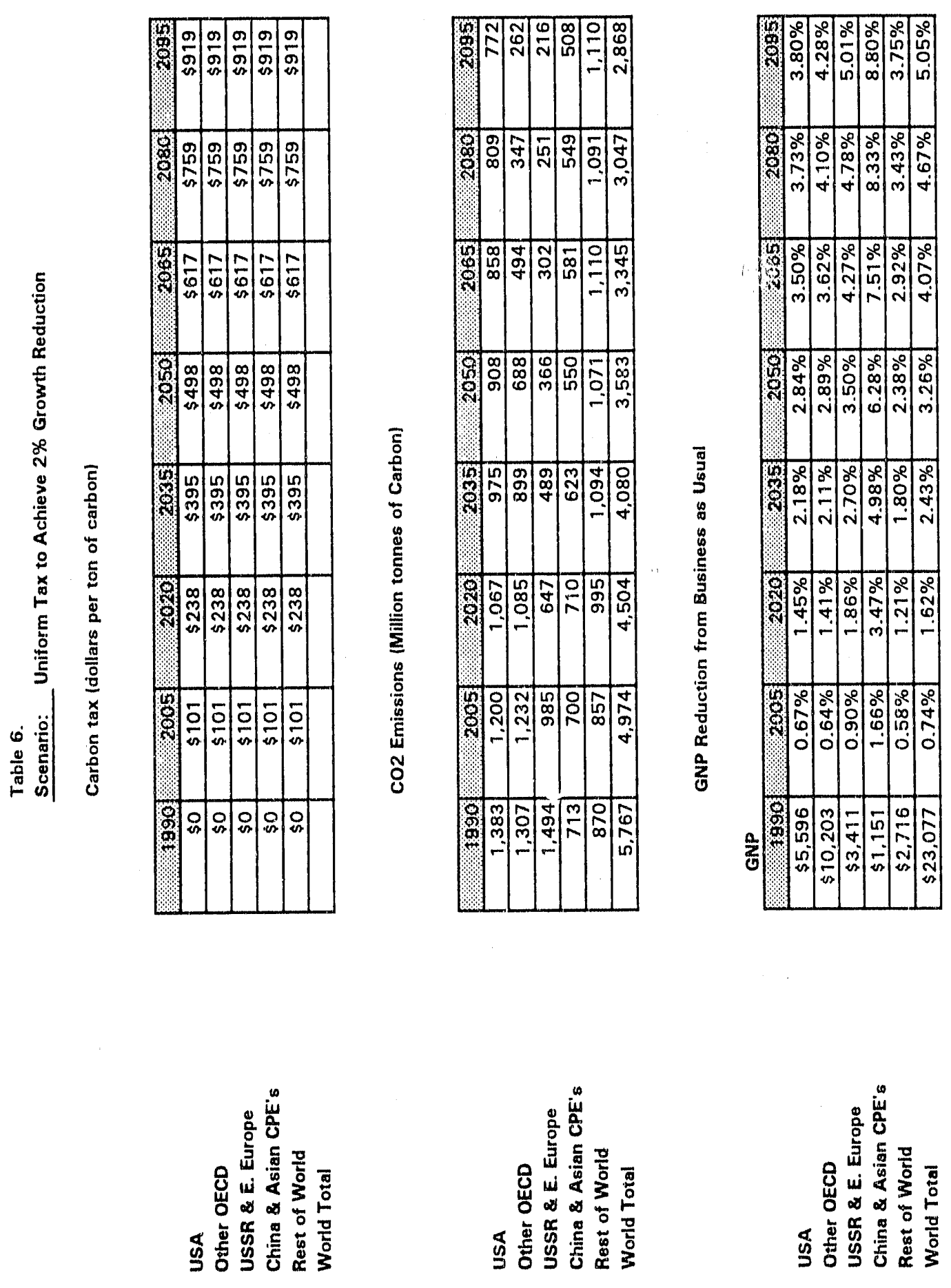


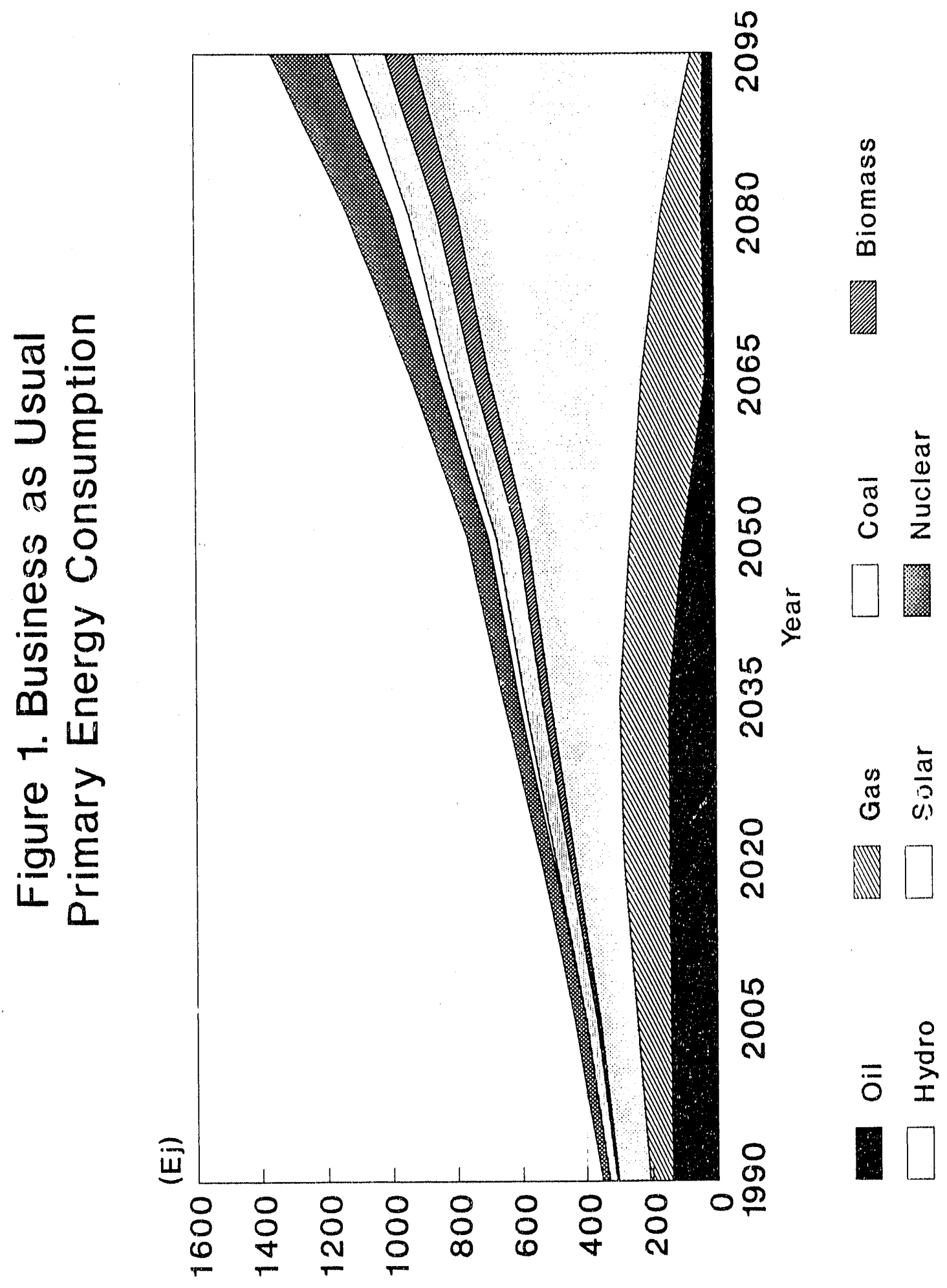

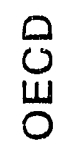




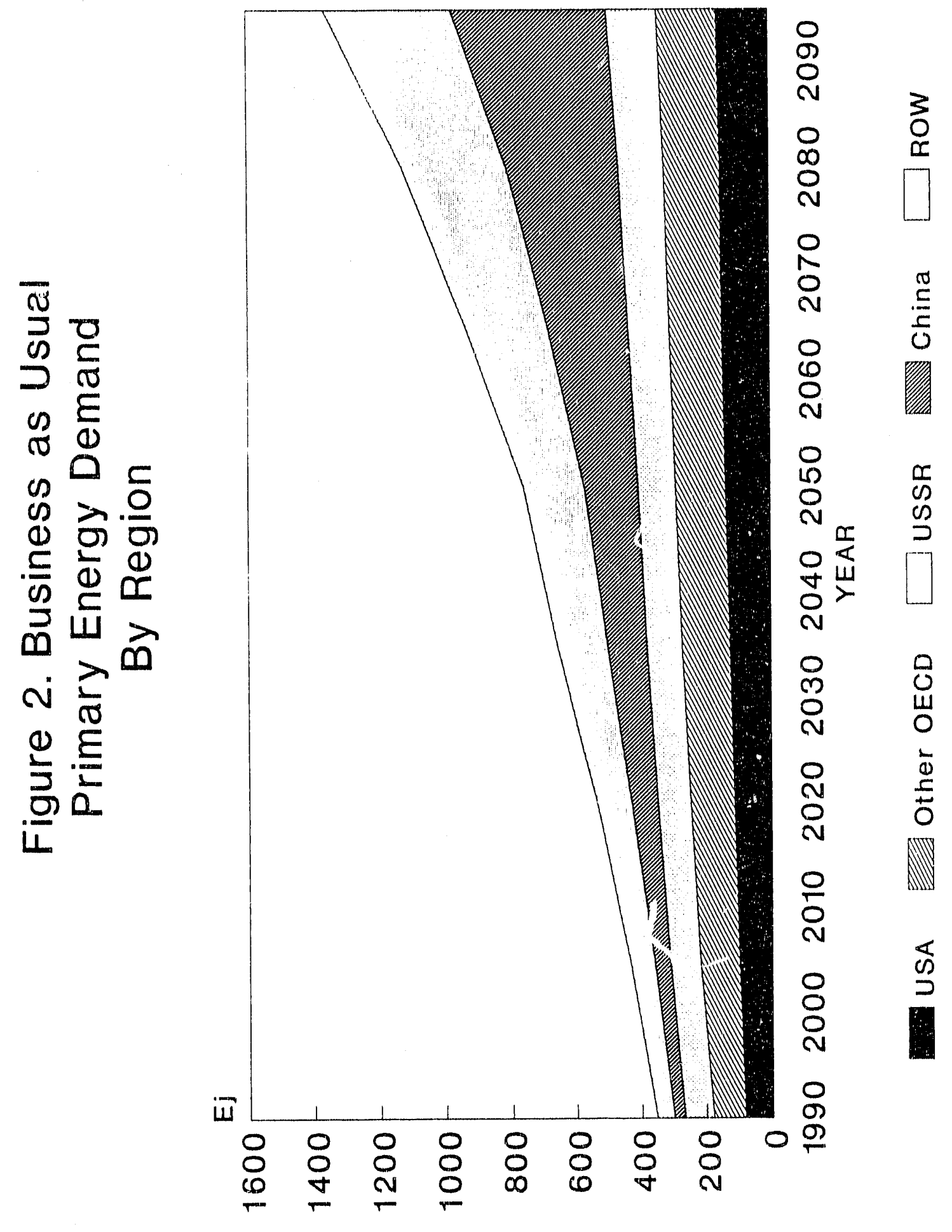

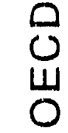




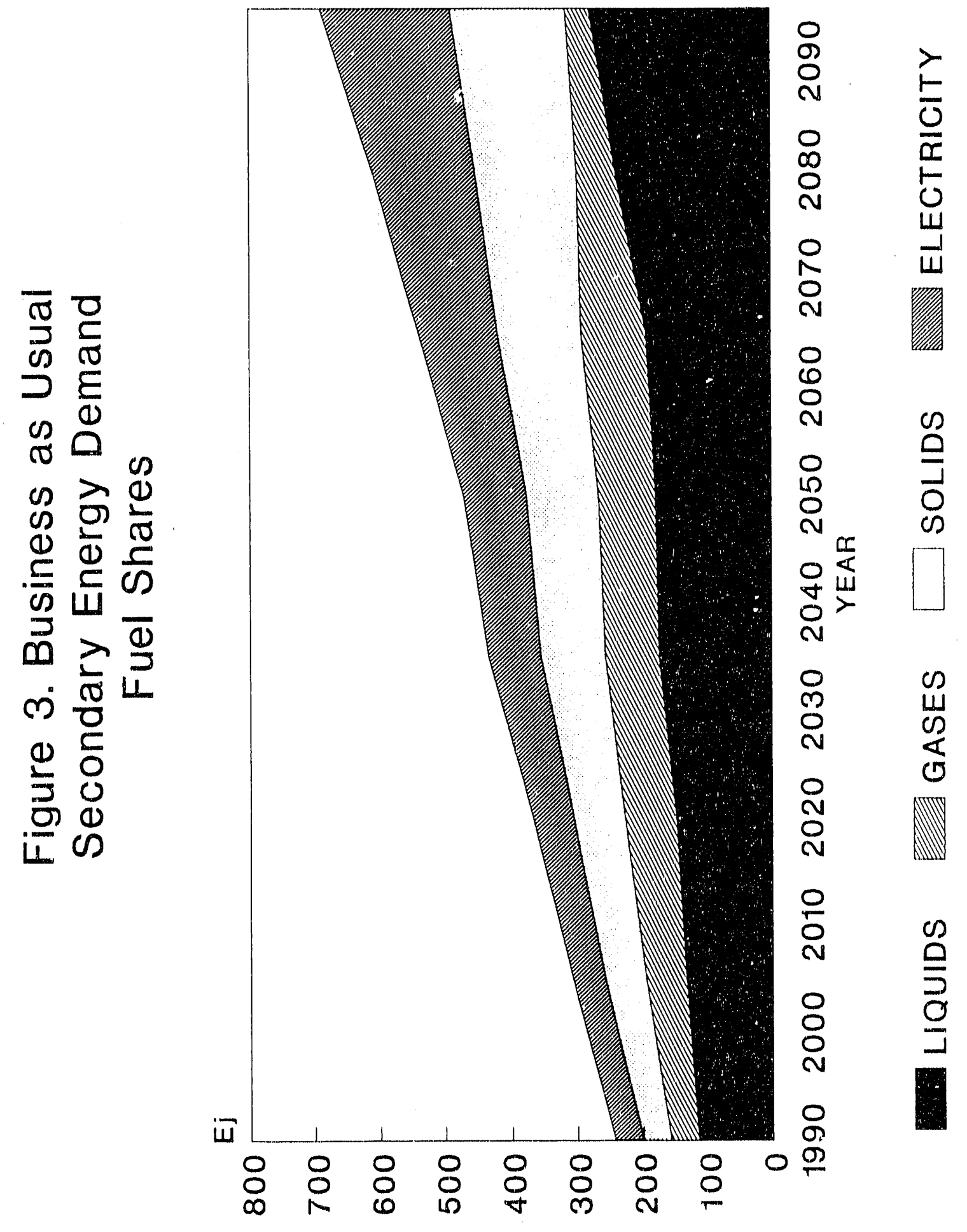

0
0 


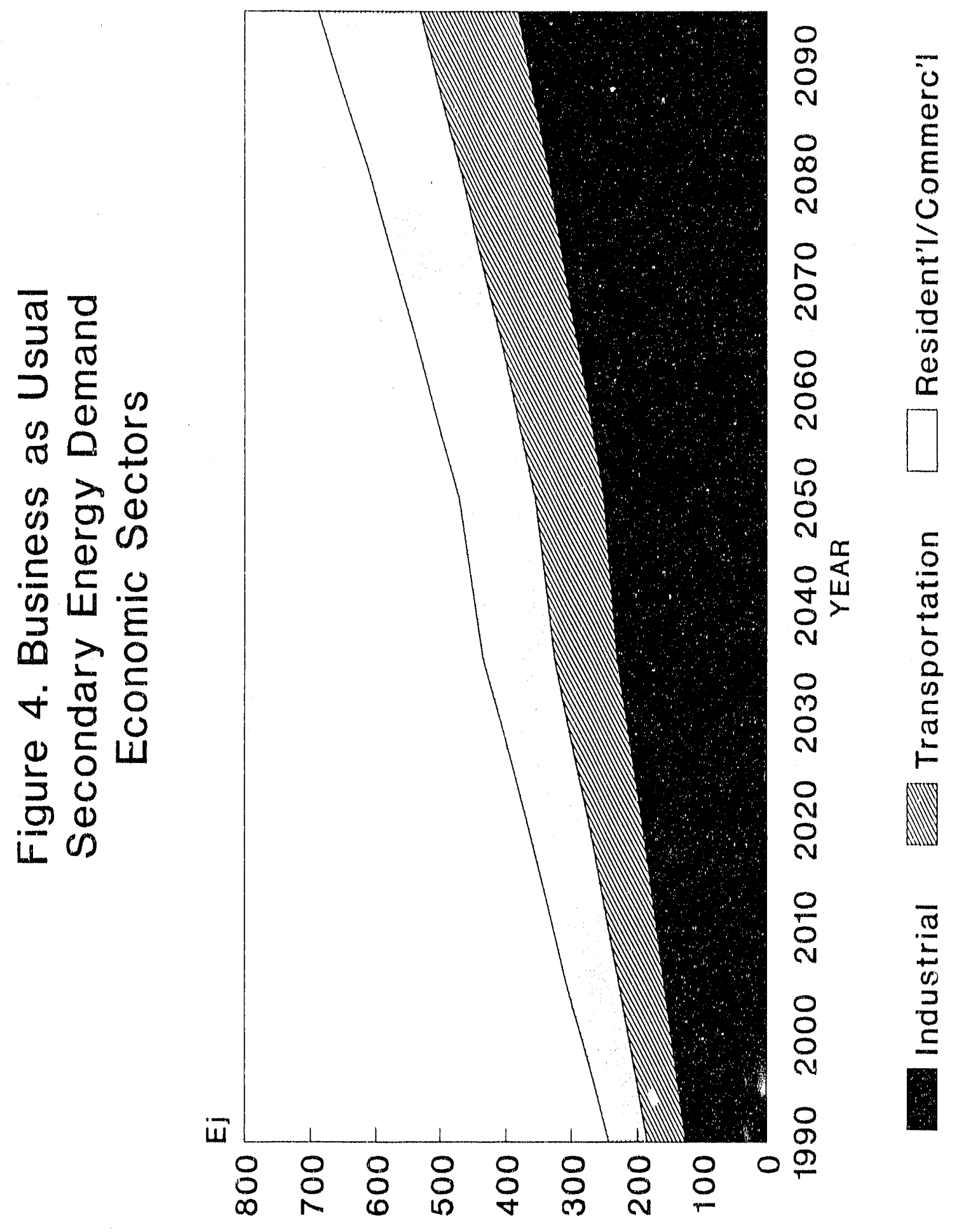

0
0
0 


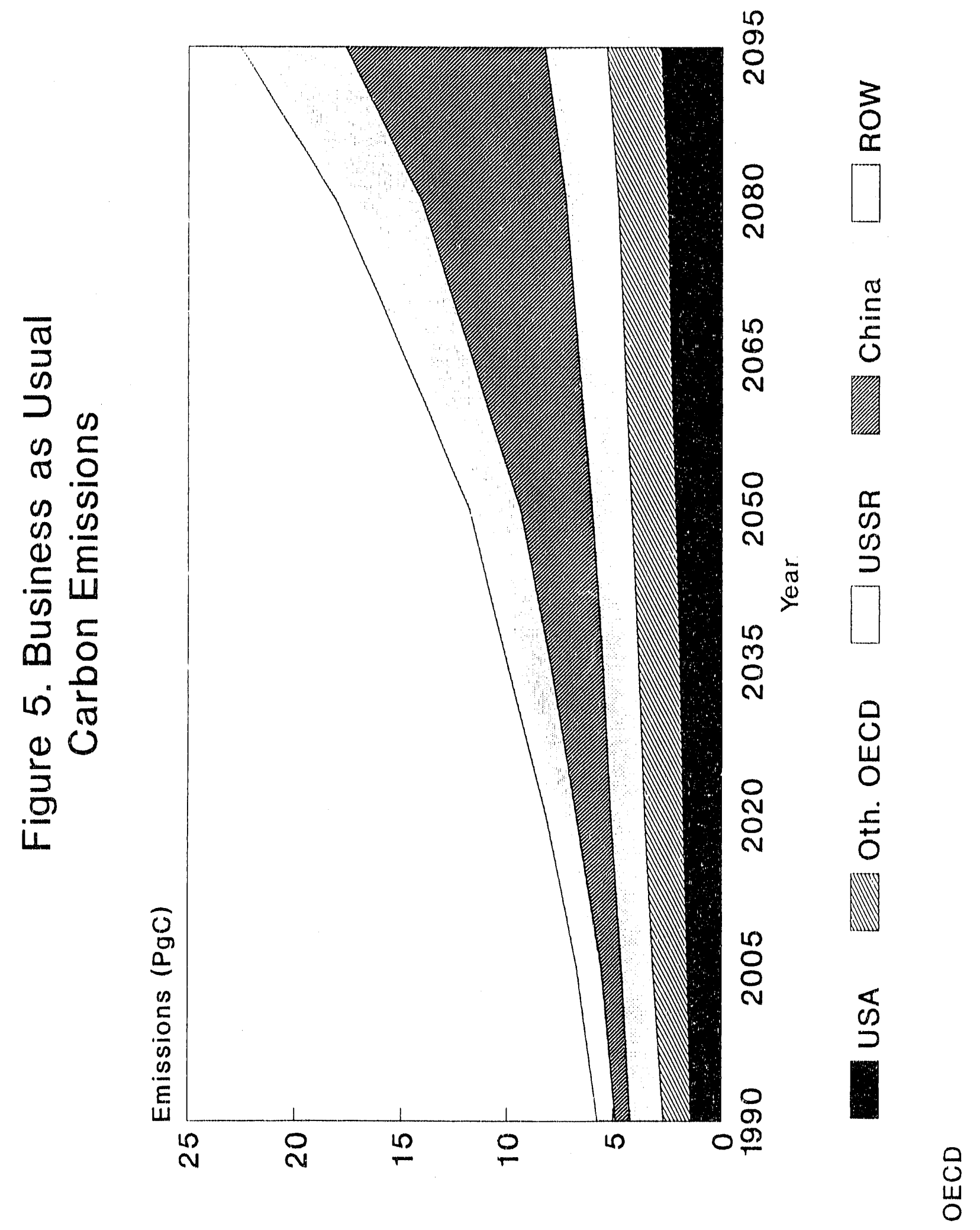




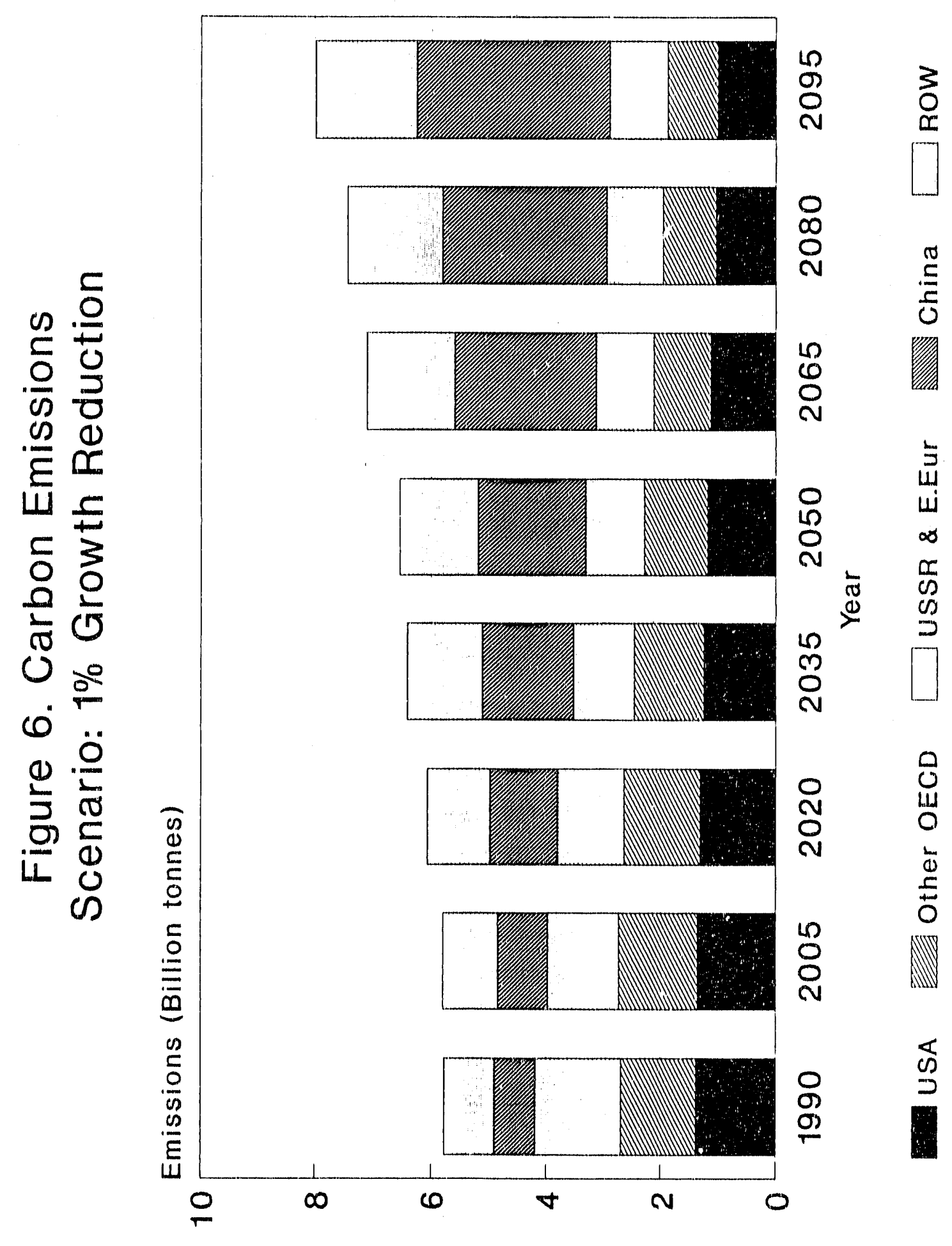

0
0
0 


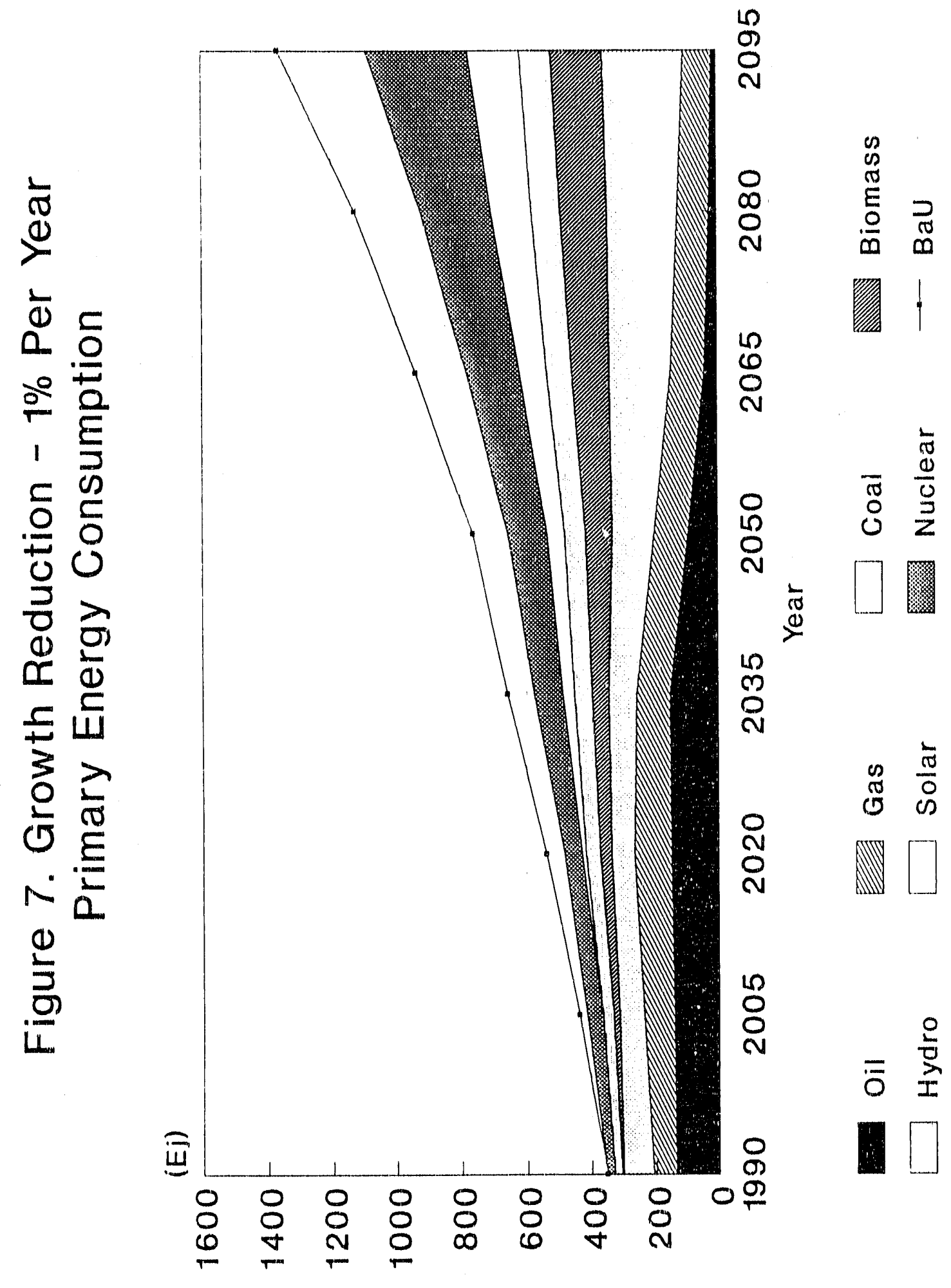

0
0
0 


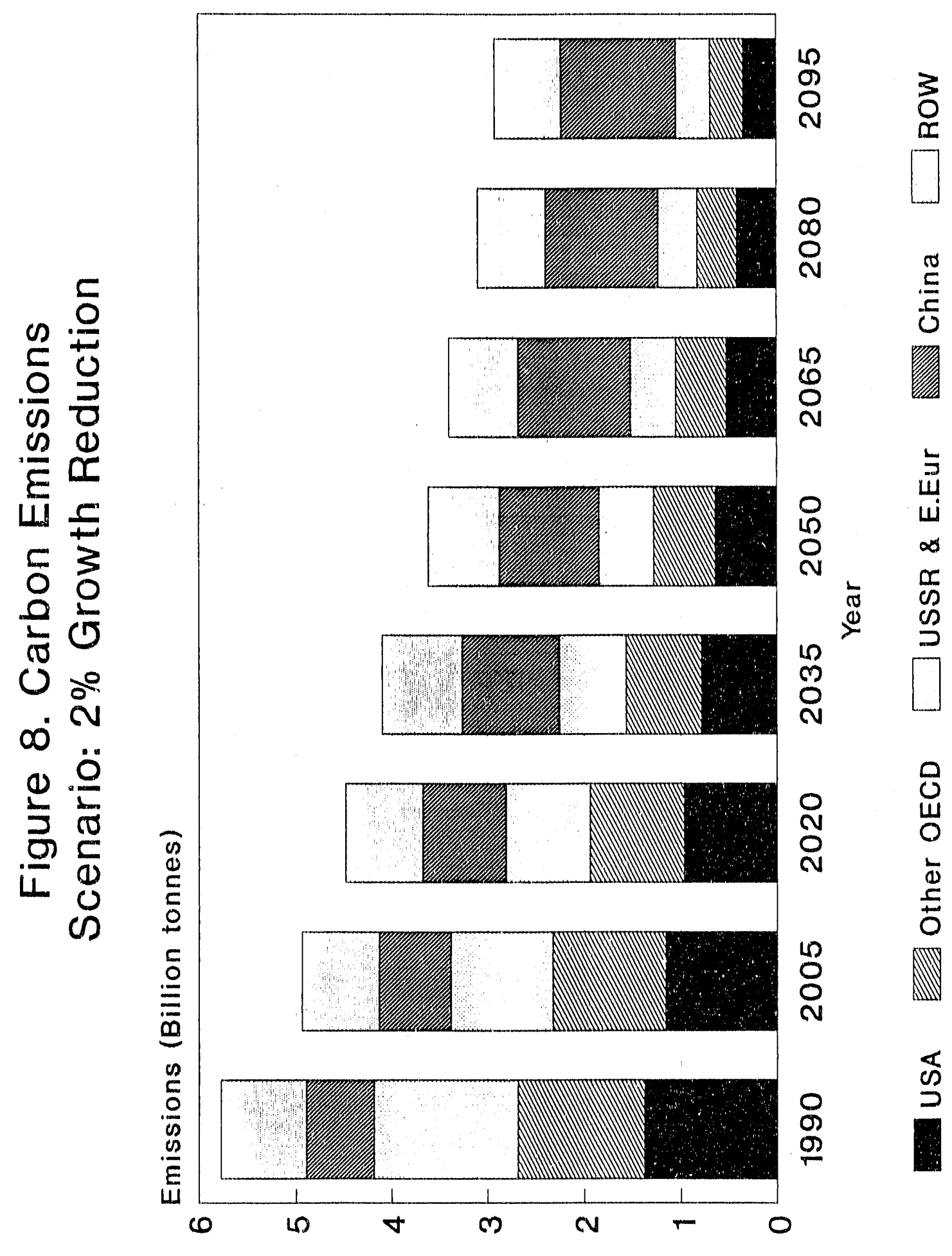

0
0
0 


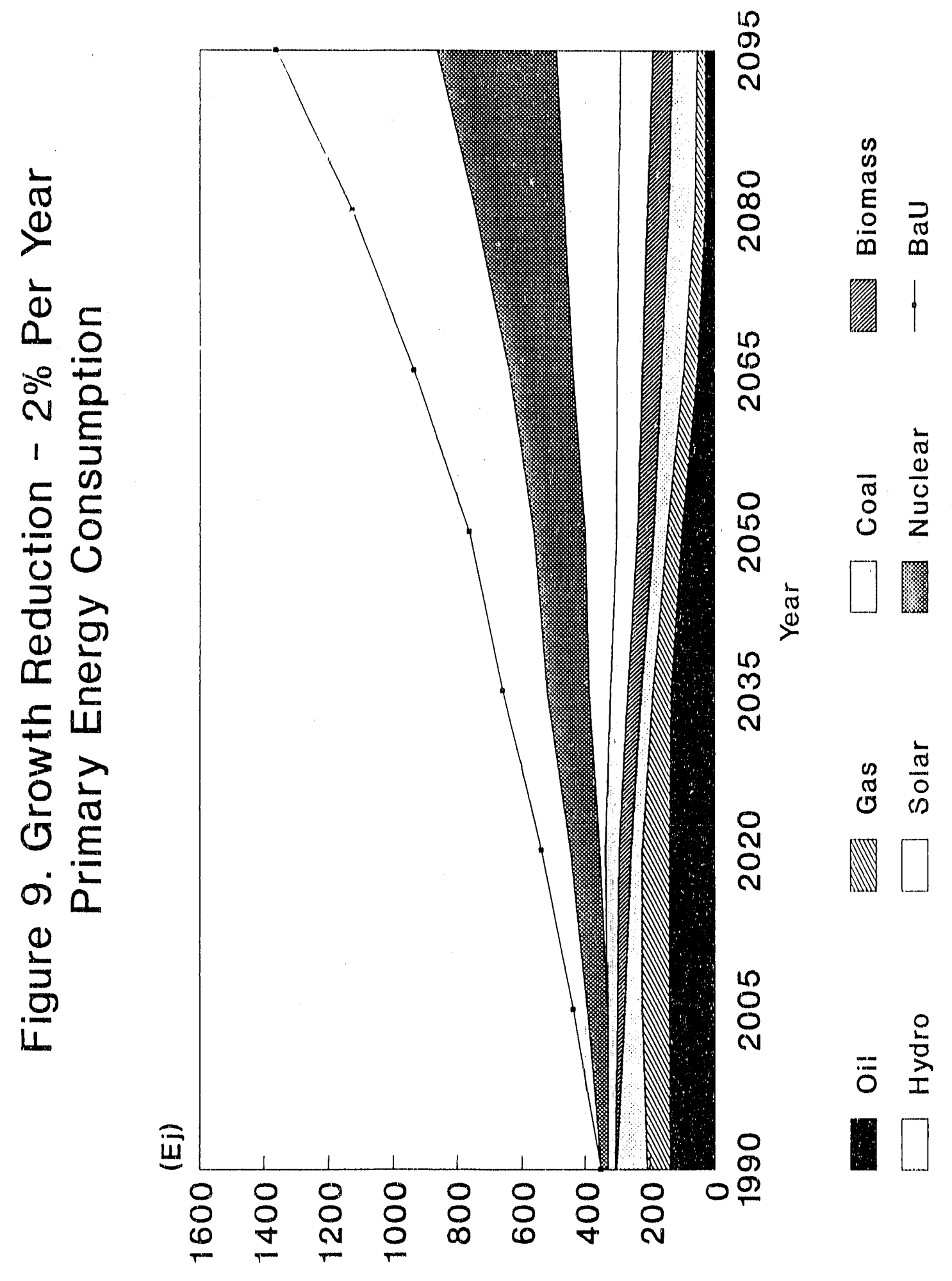

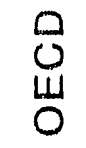




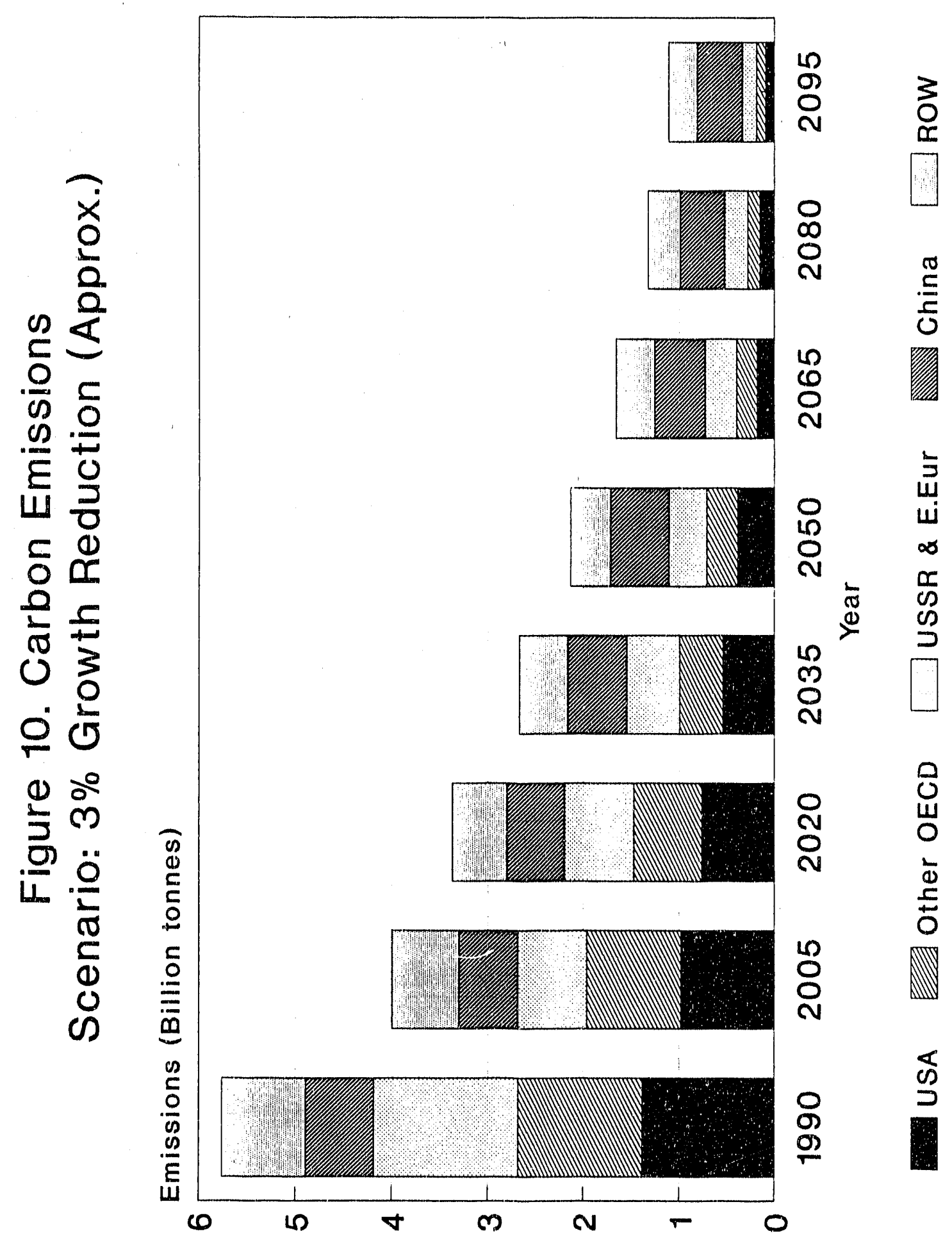

0
0
0 


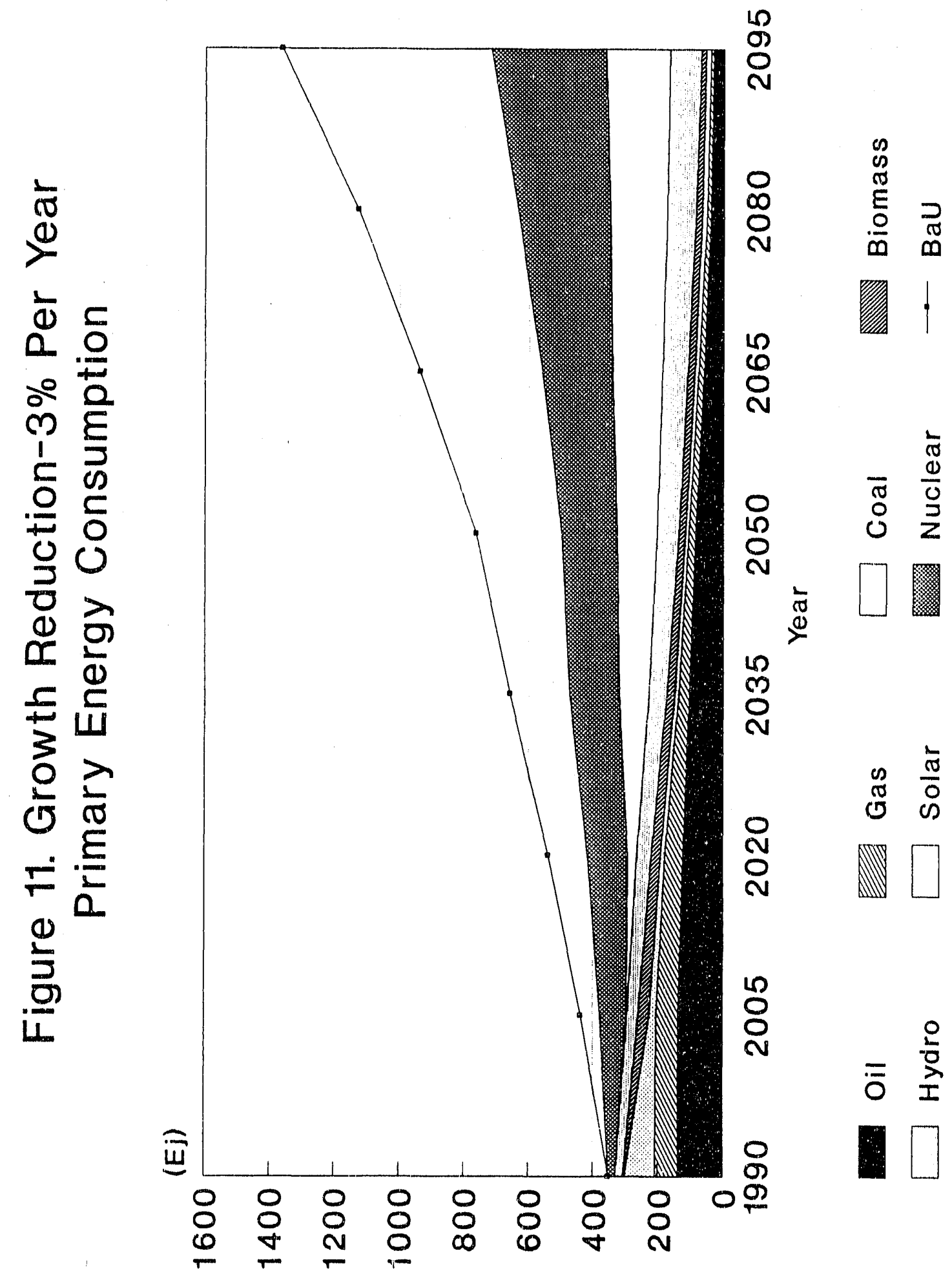

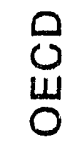




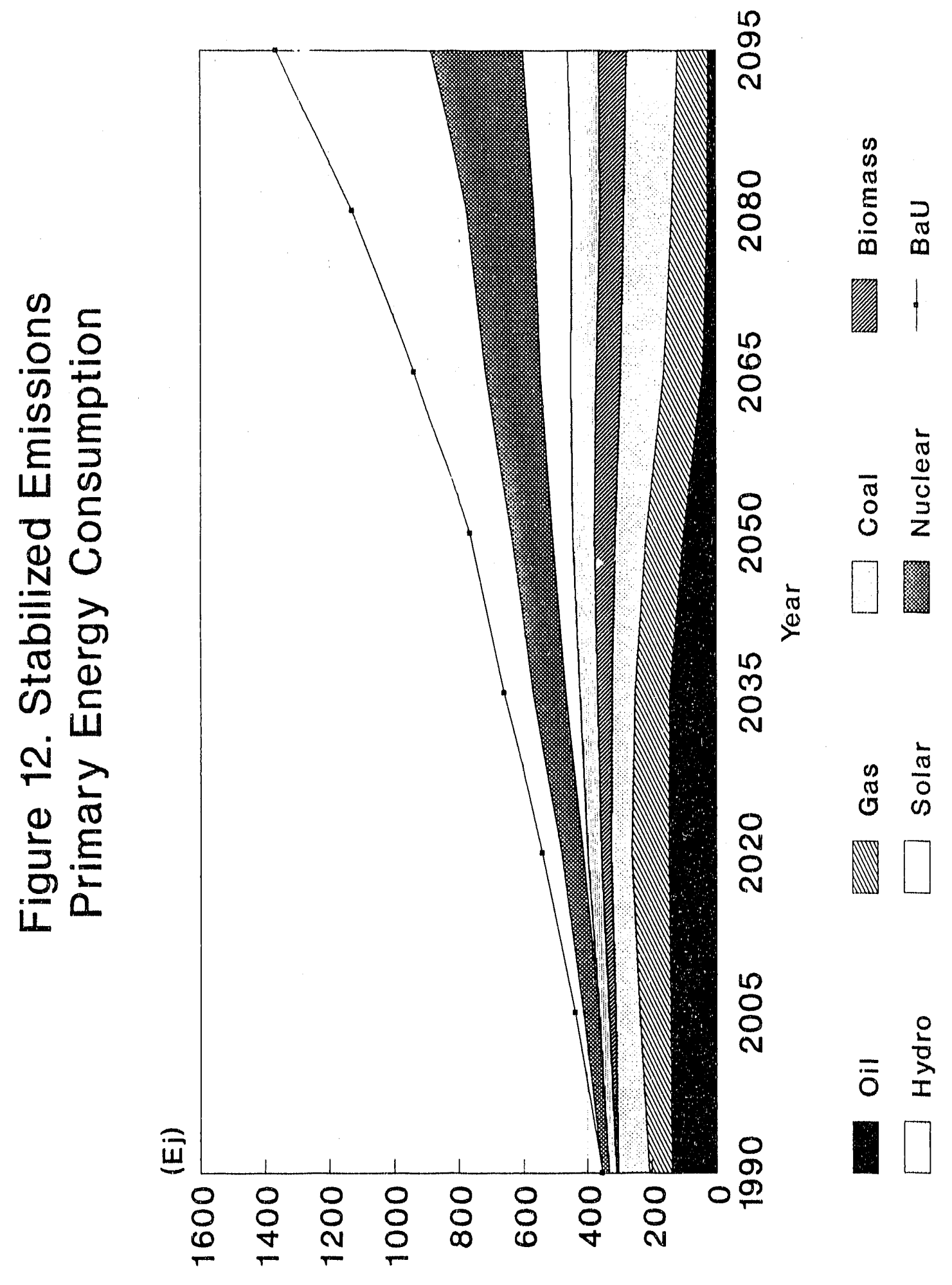

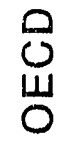




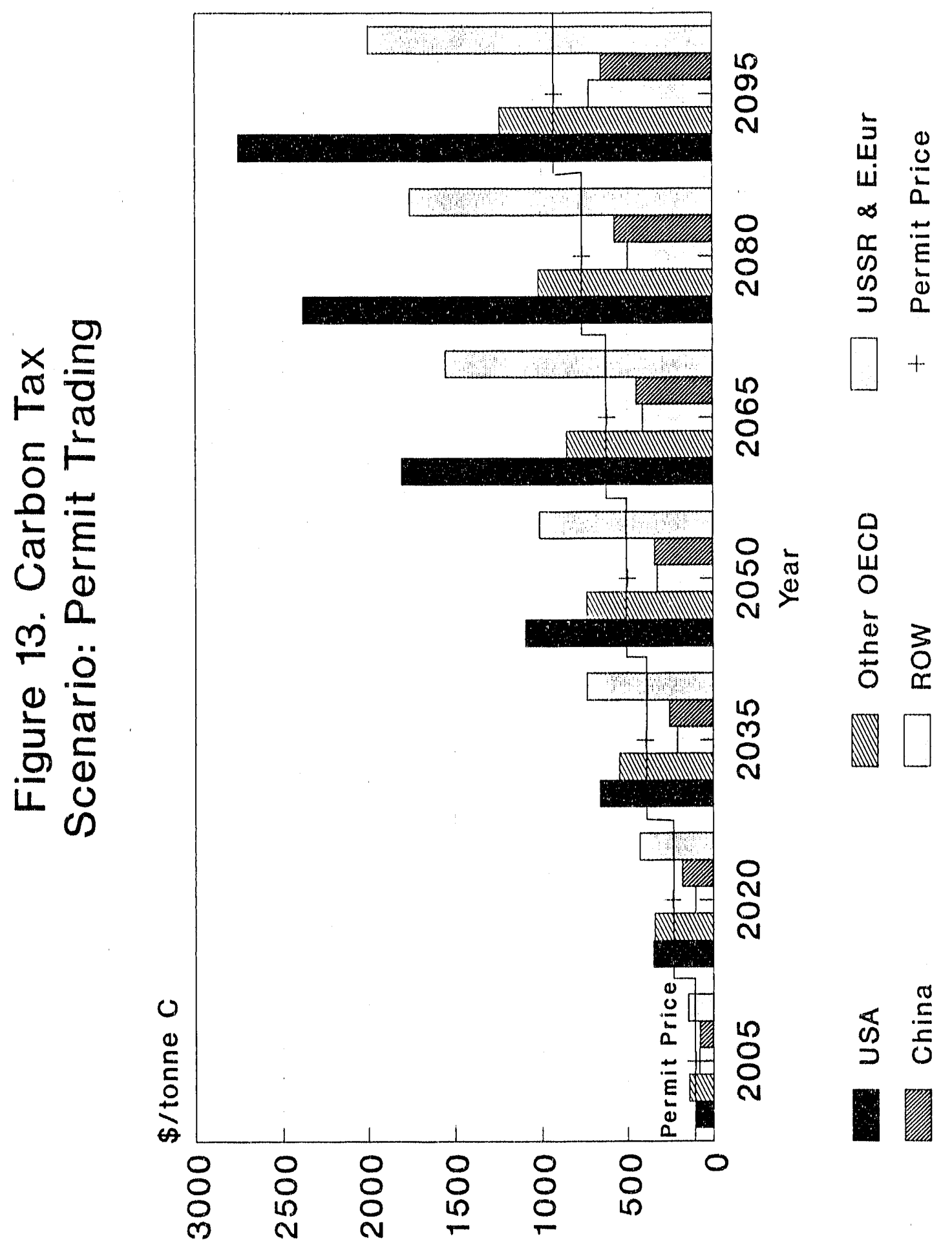

总 


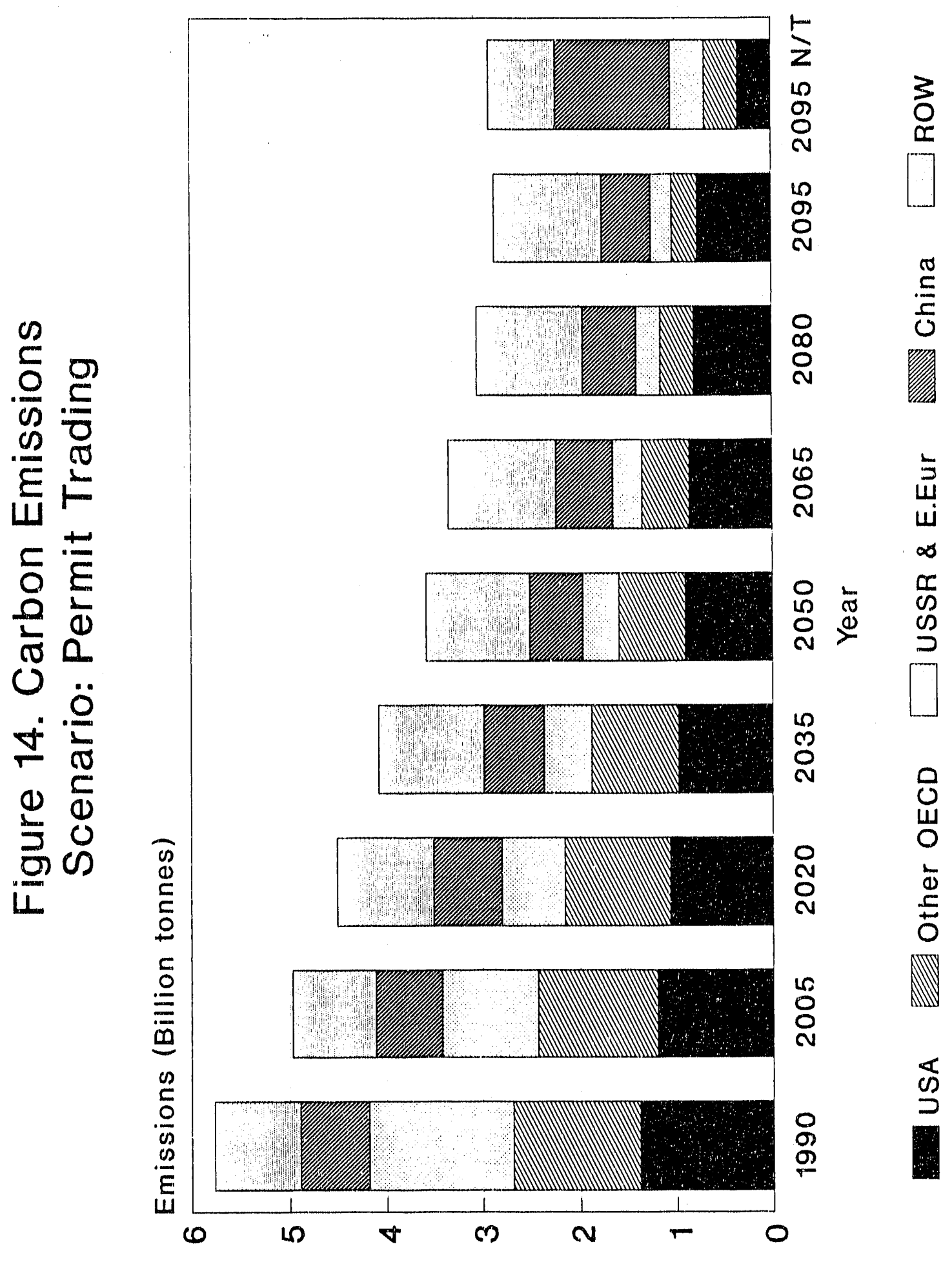

岂 


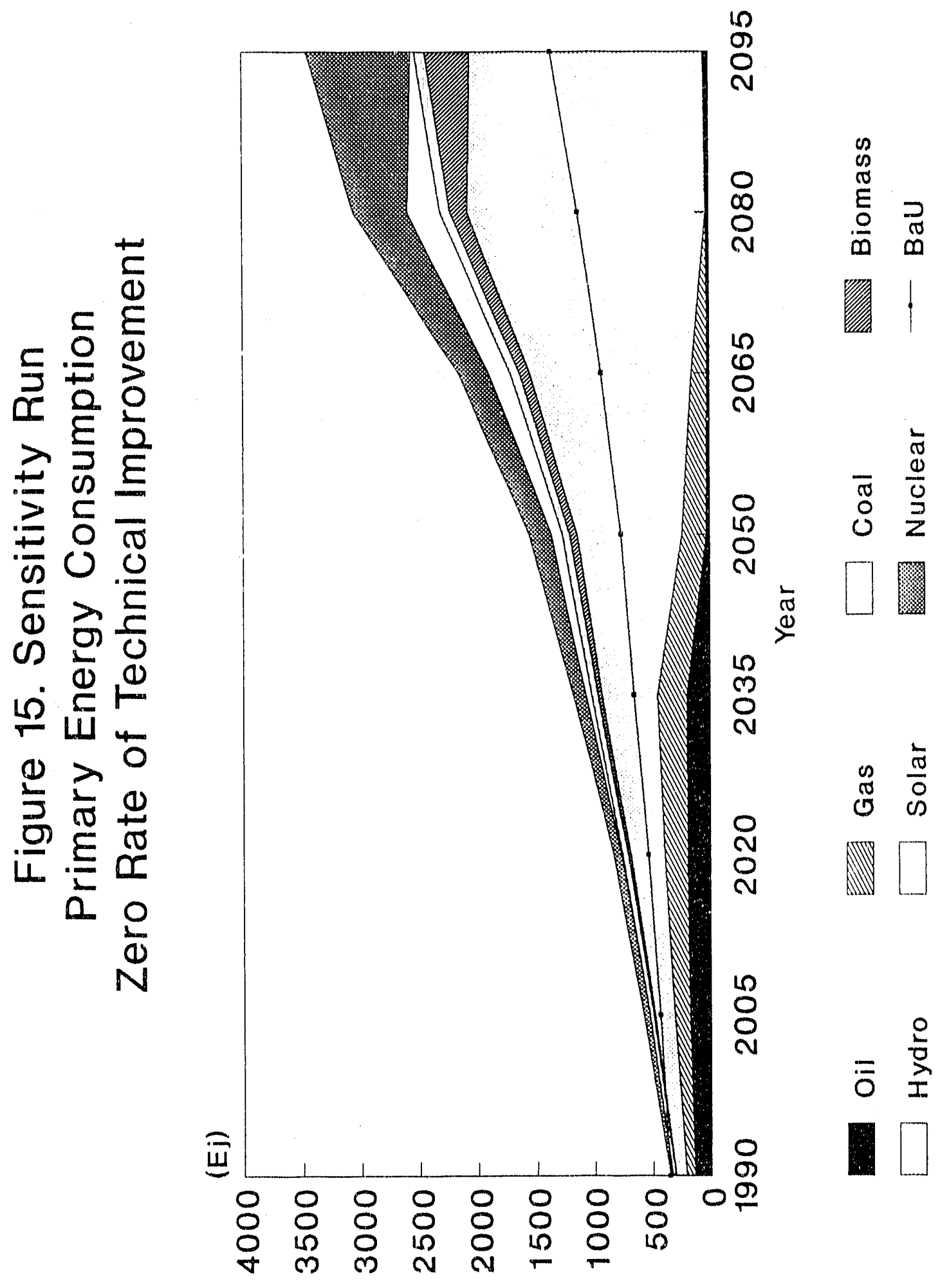

怤 


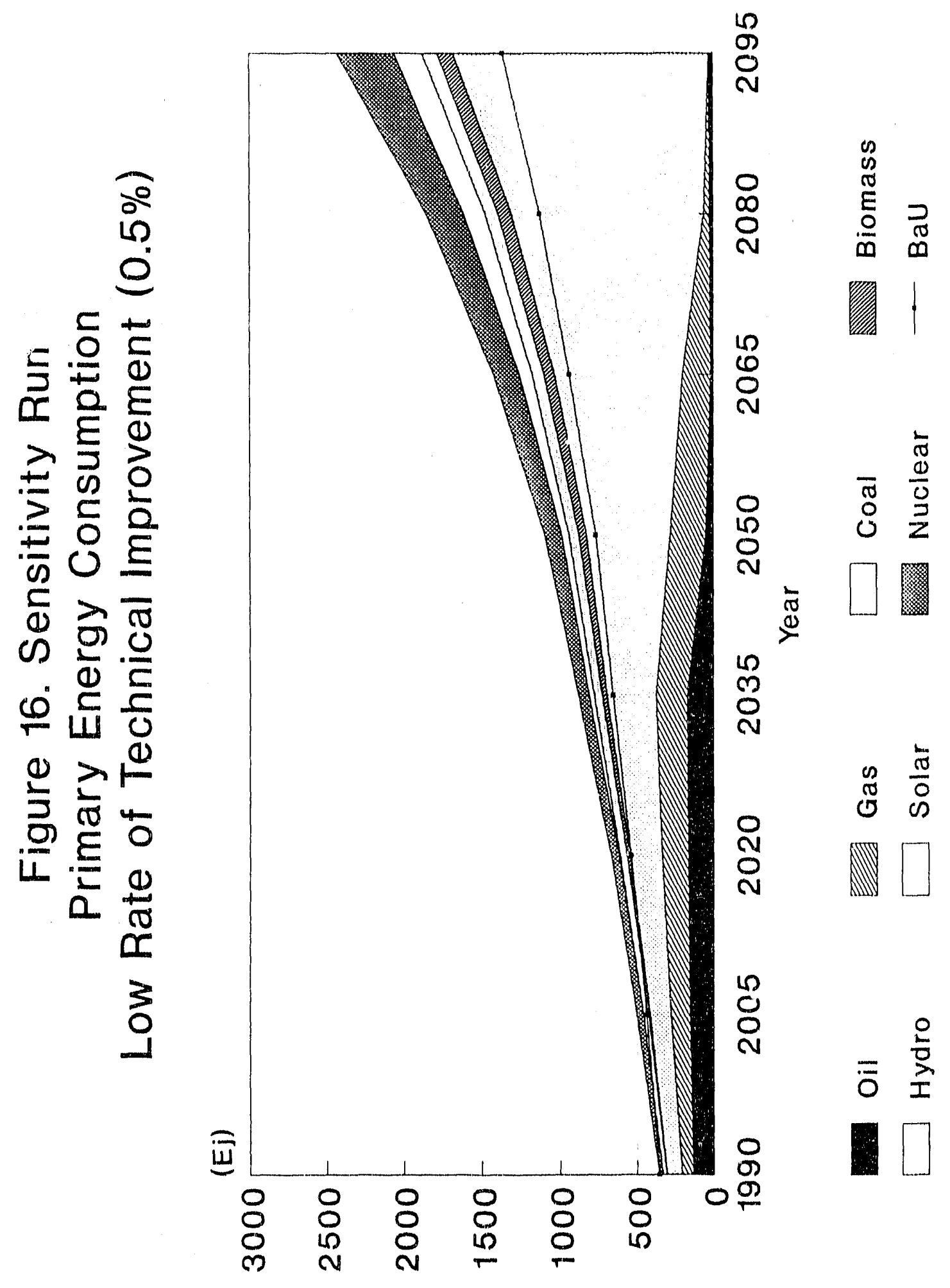

0
0
0 


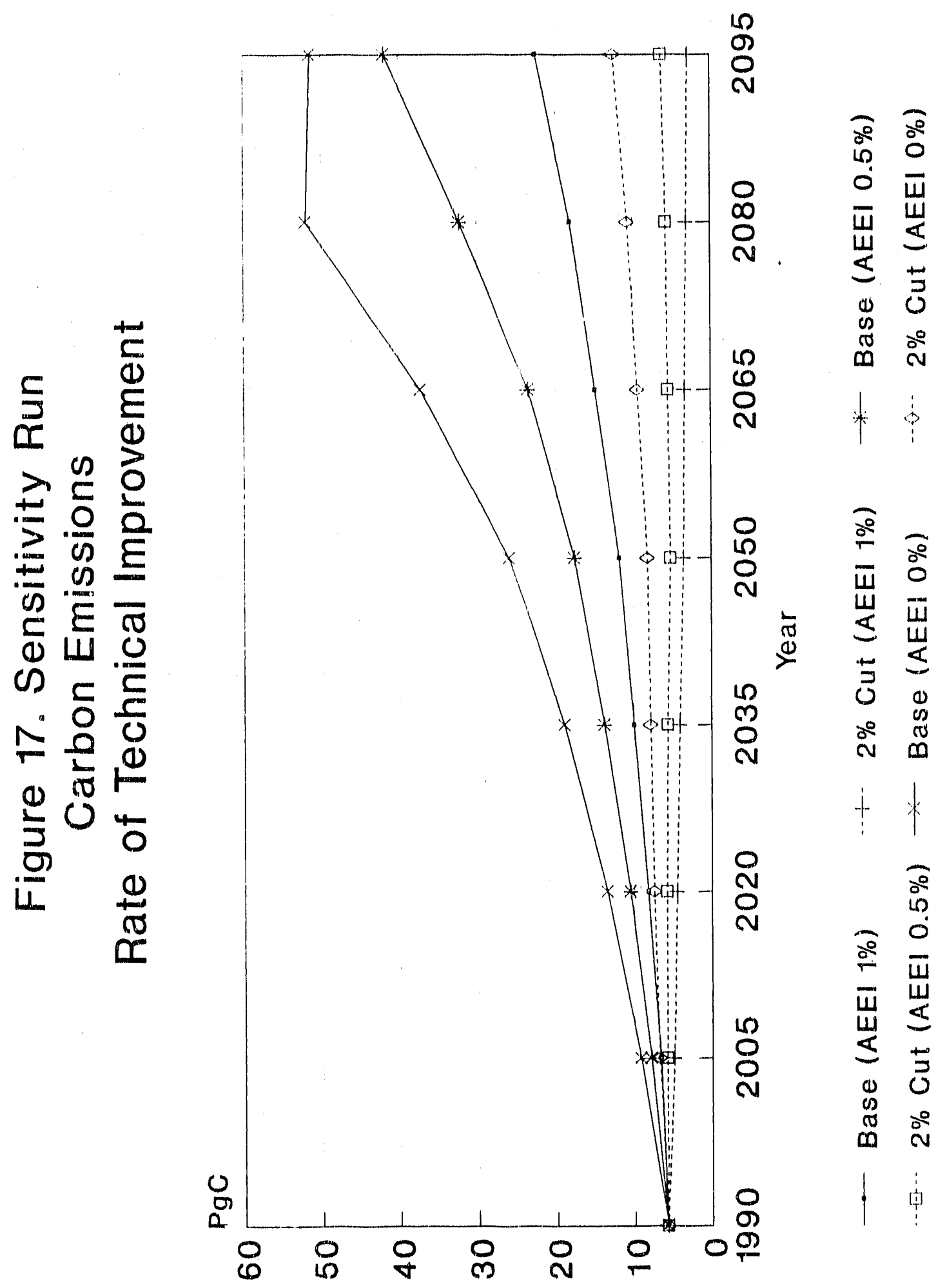

总 


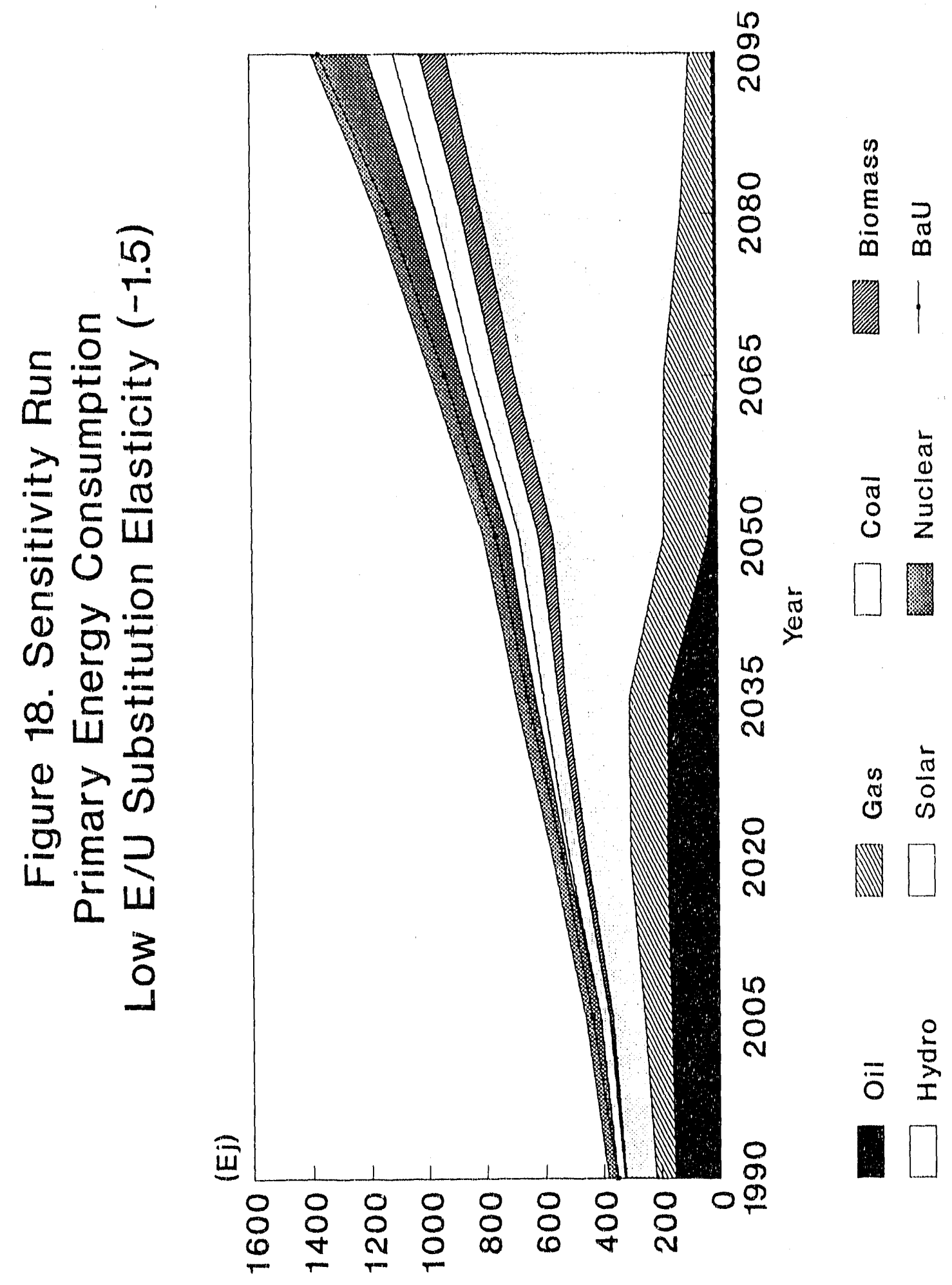

$\underset{0}{0}$ 


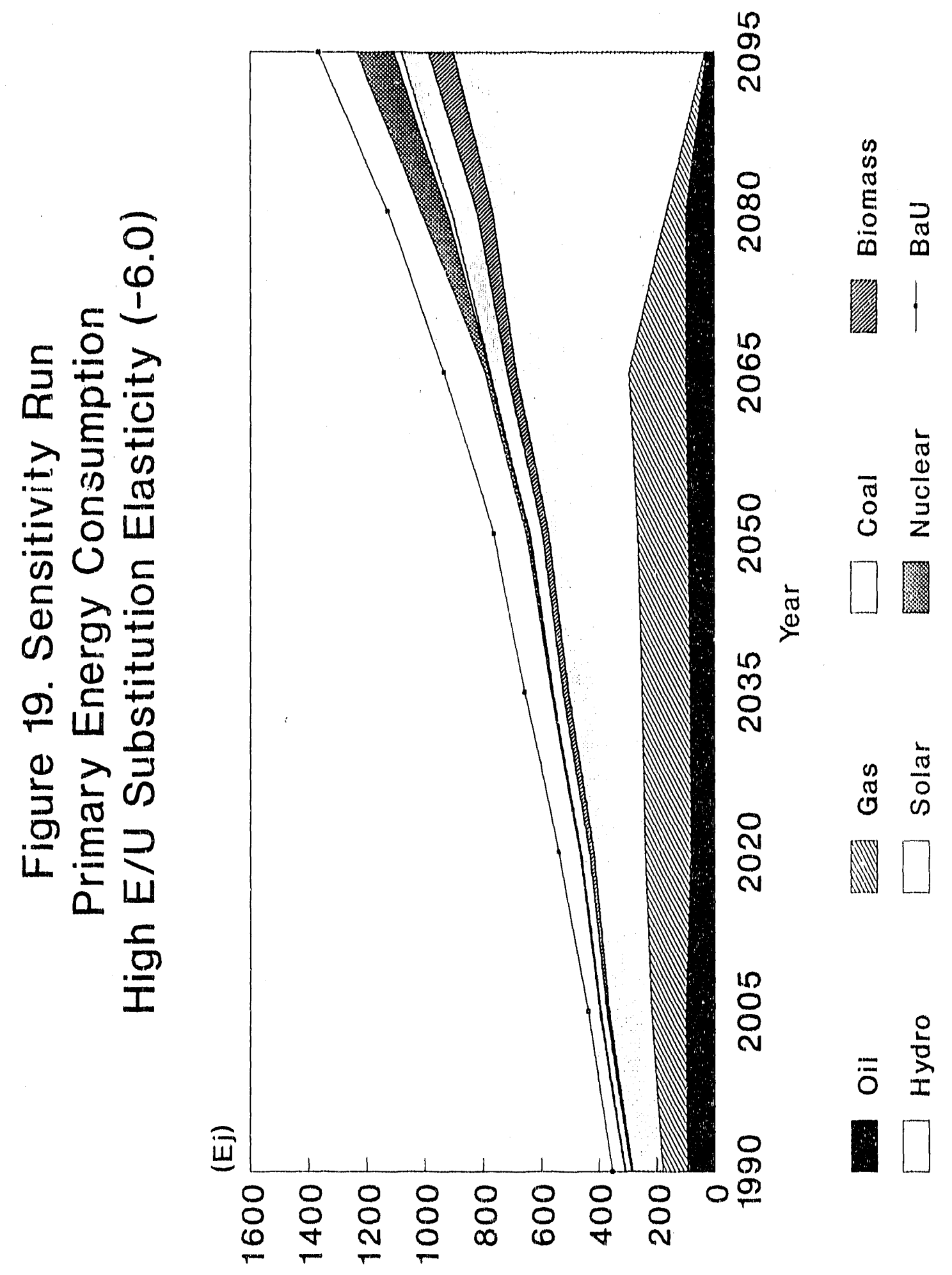

0
0
0 


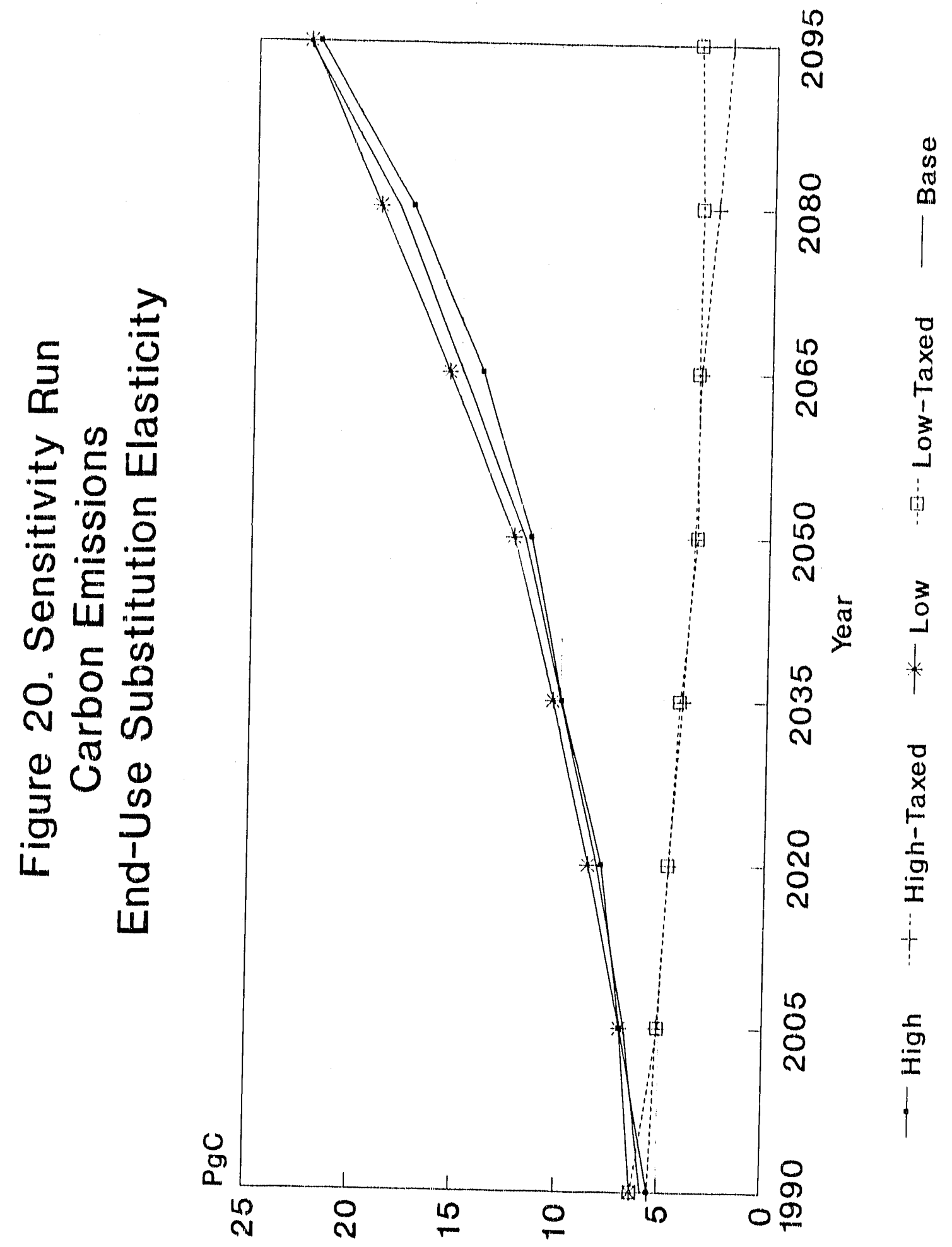

遌 


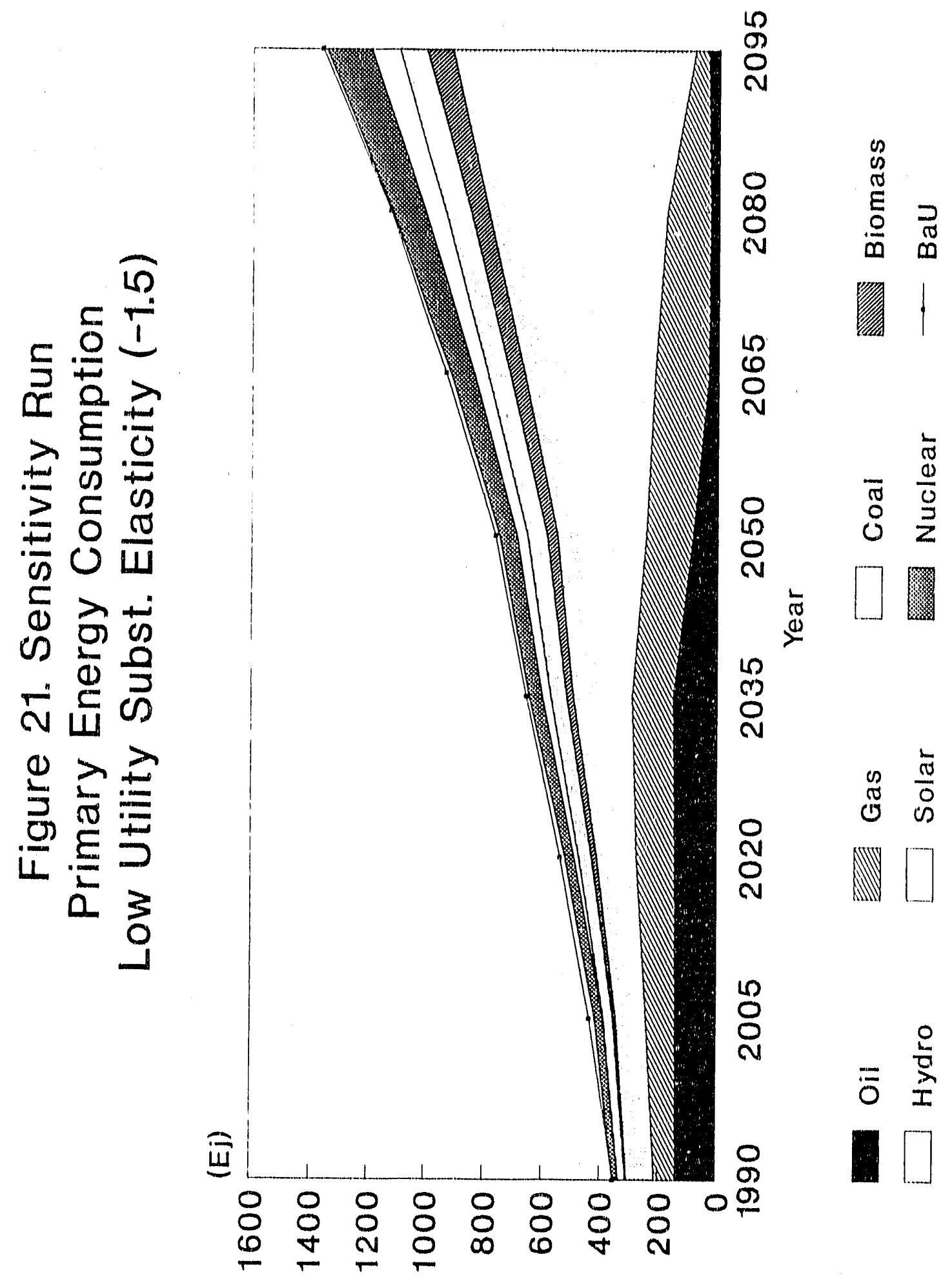

递 


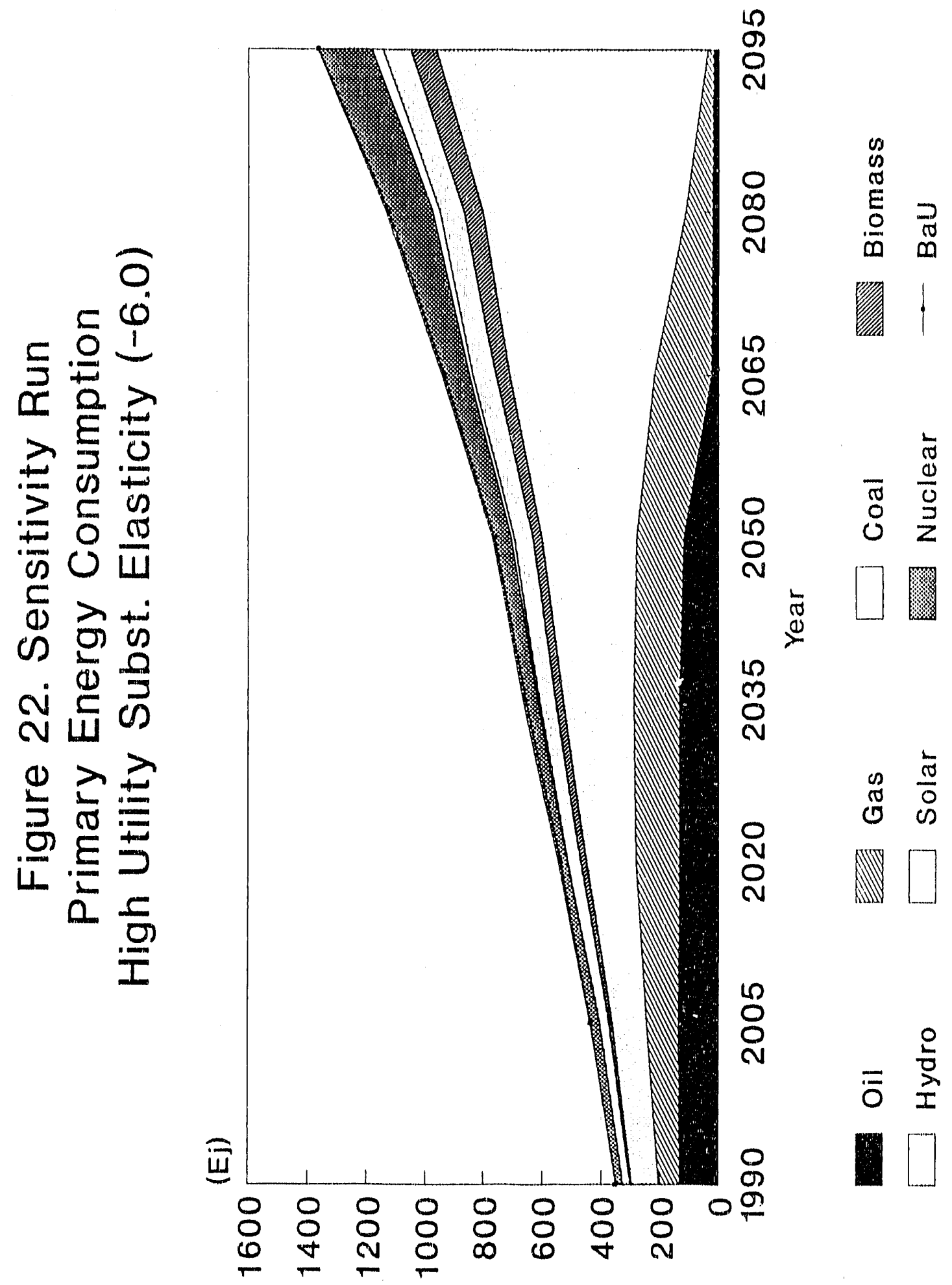

0
0
0 


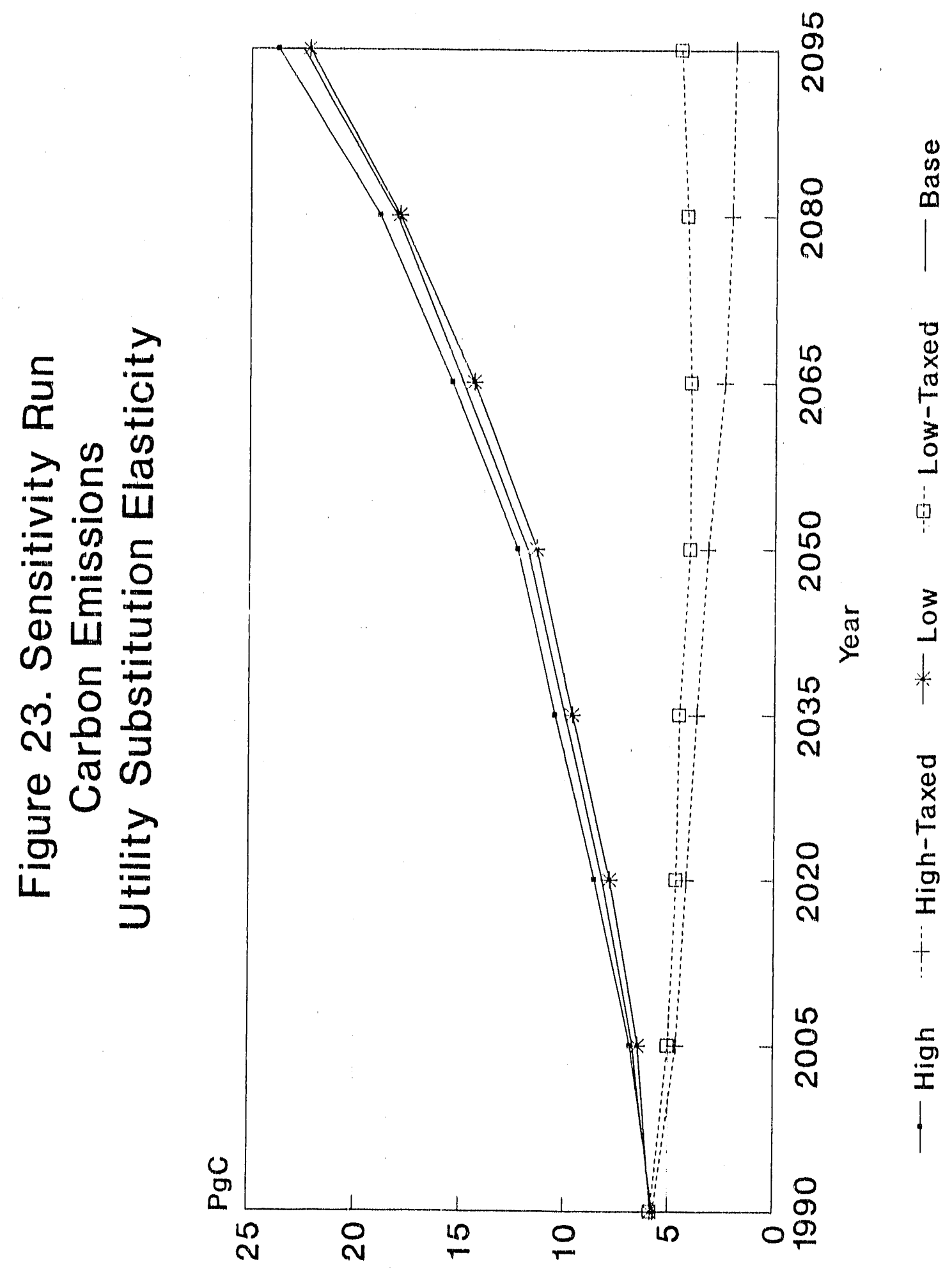

0
0
0 


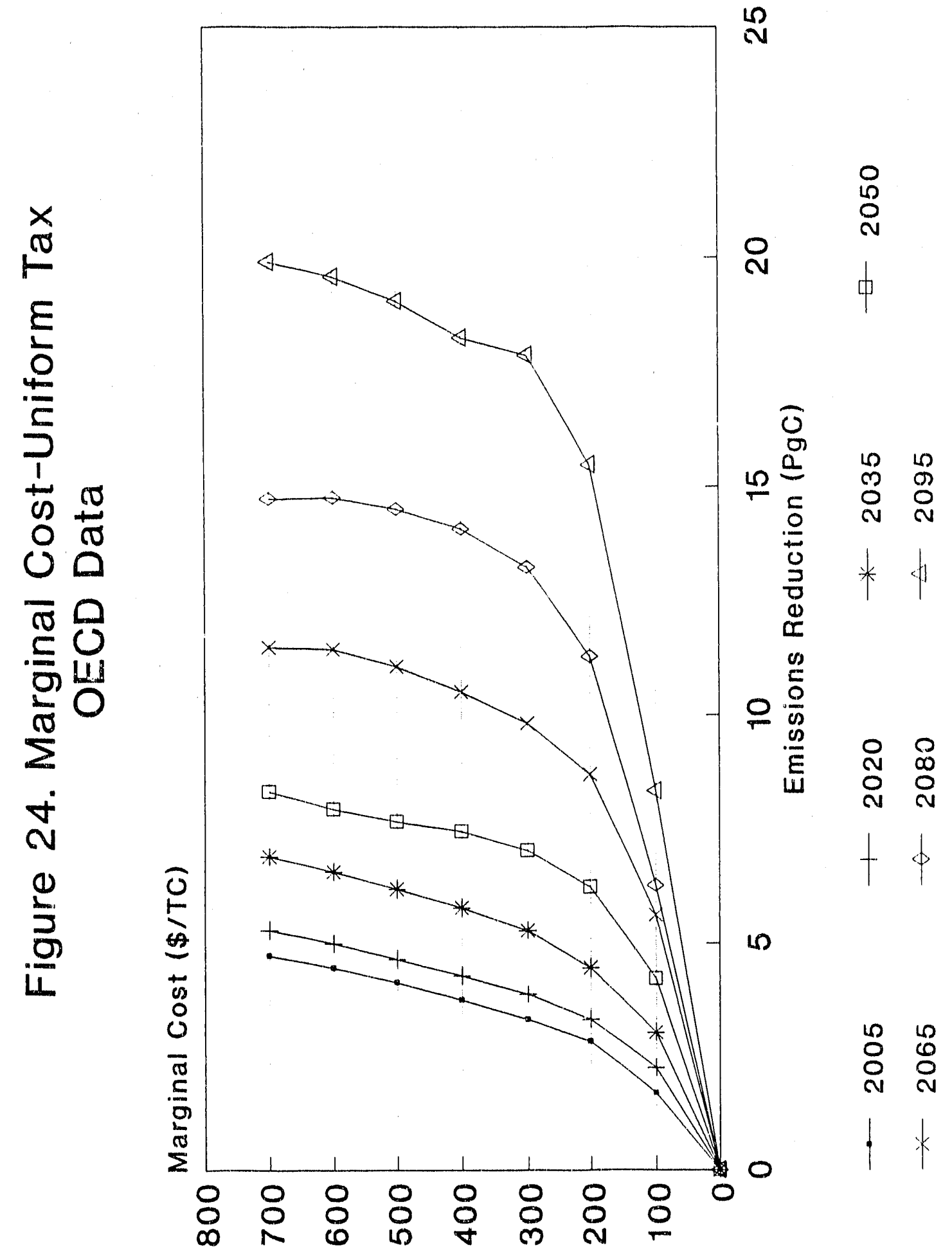

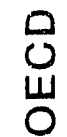




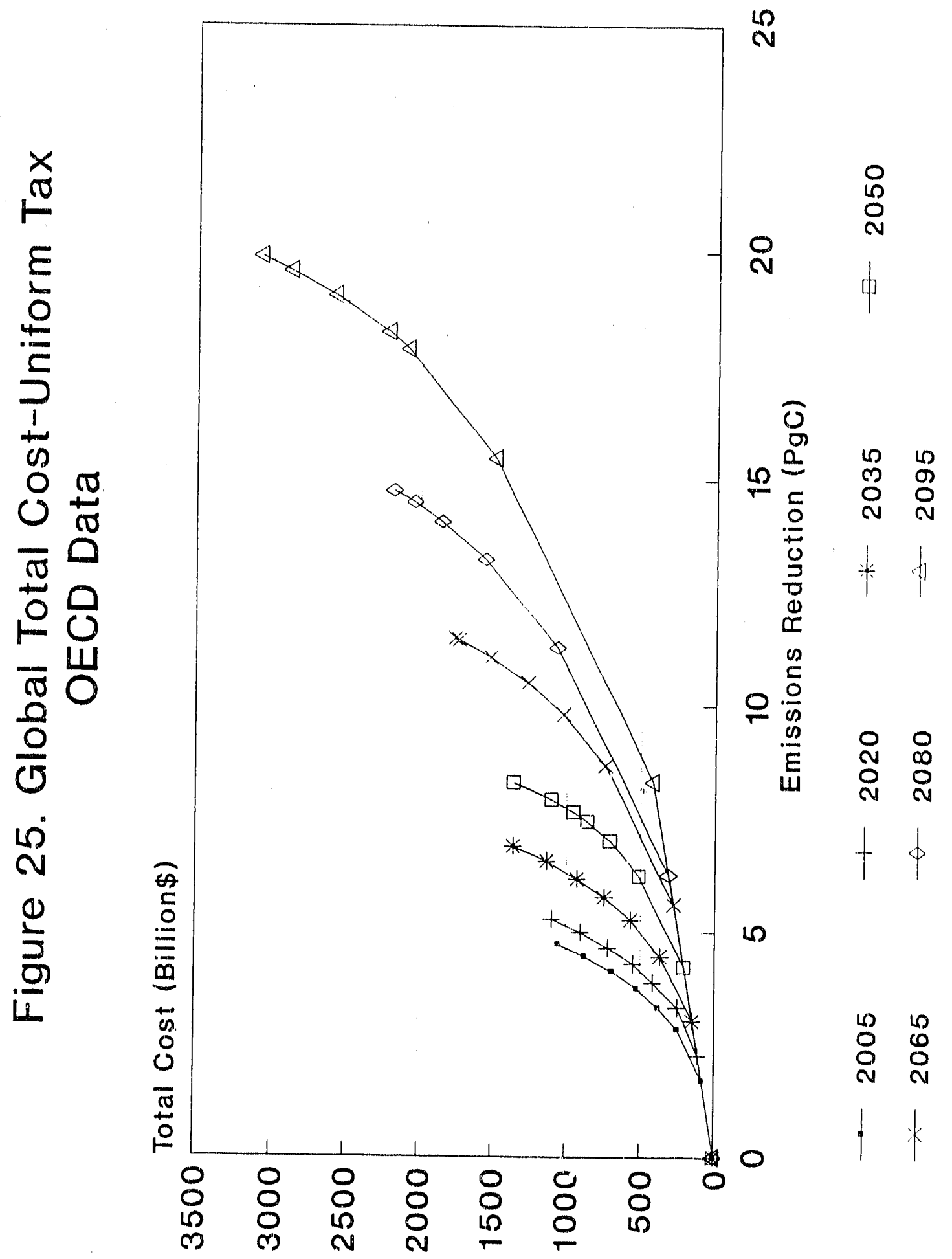

영 


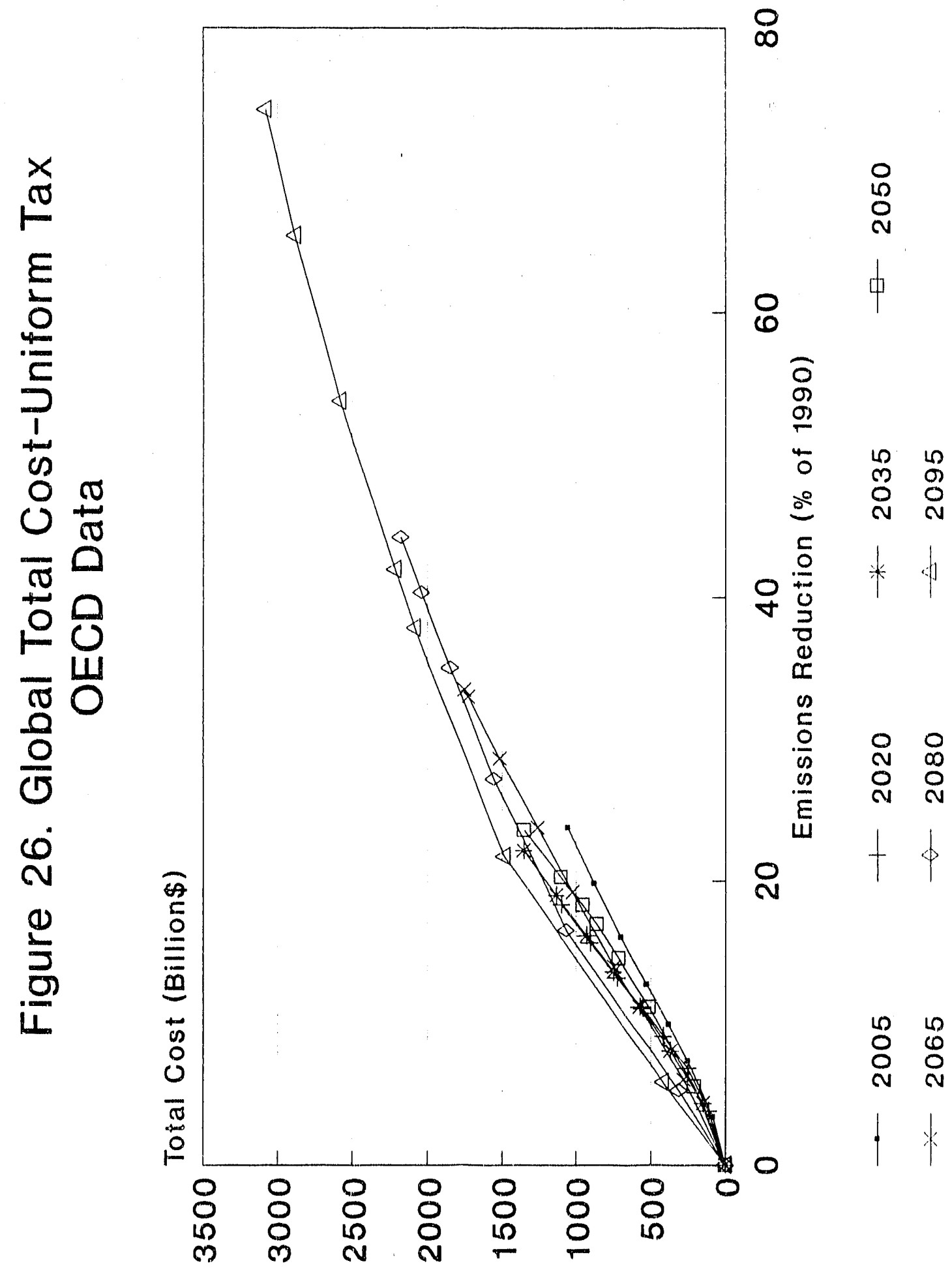

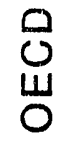




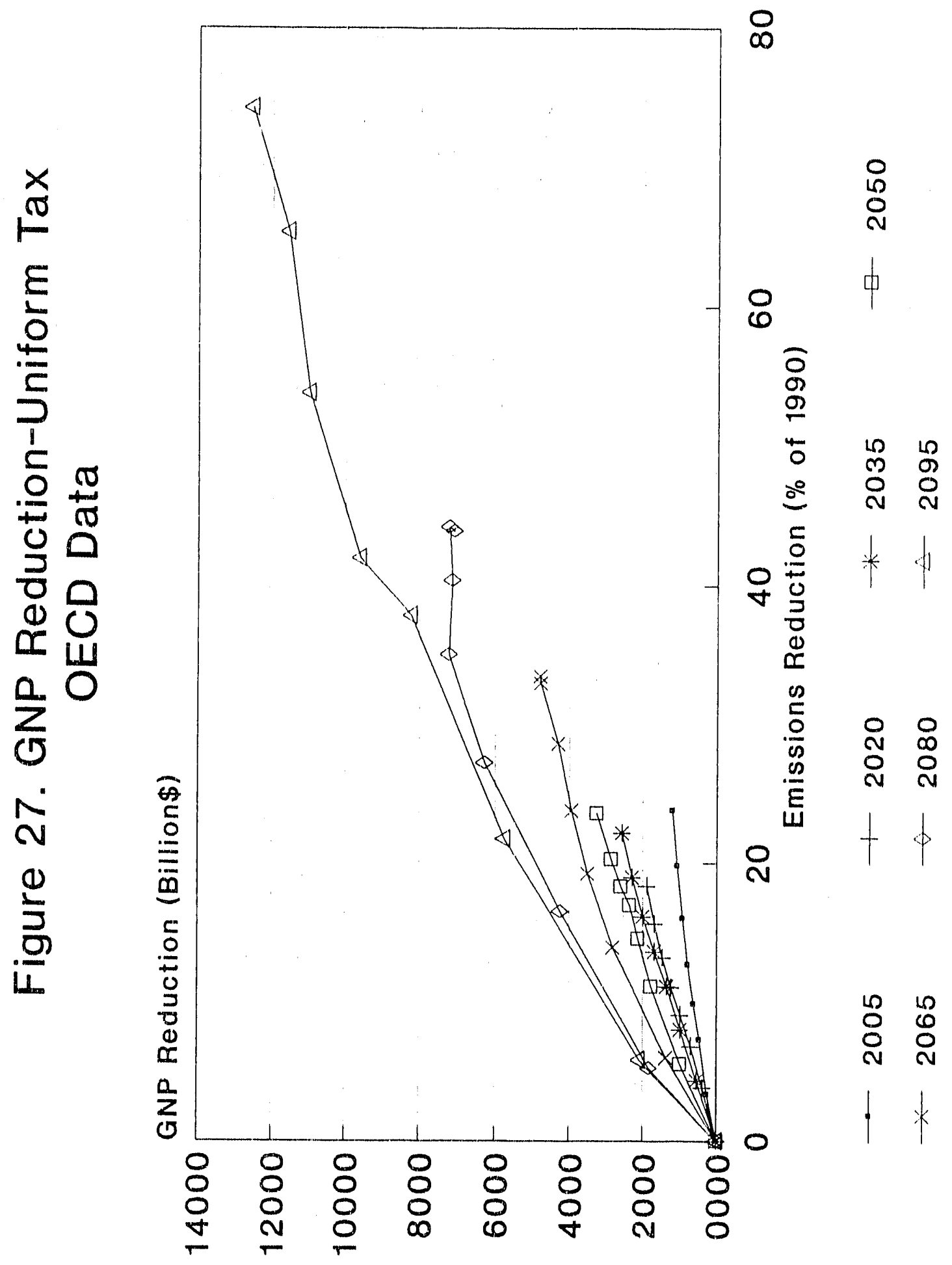

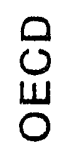




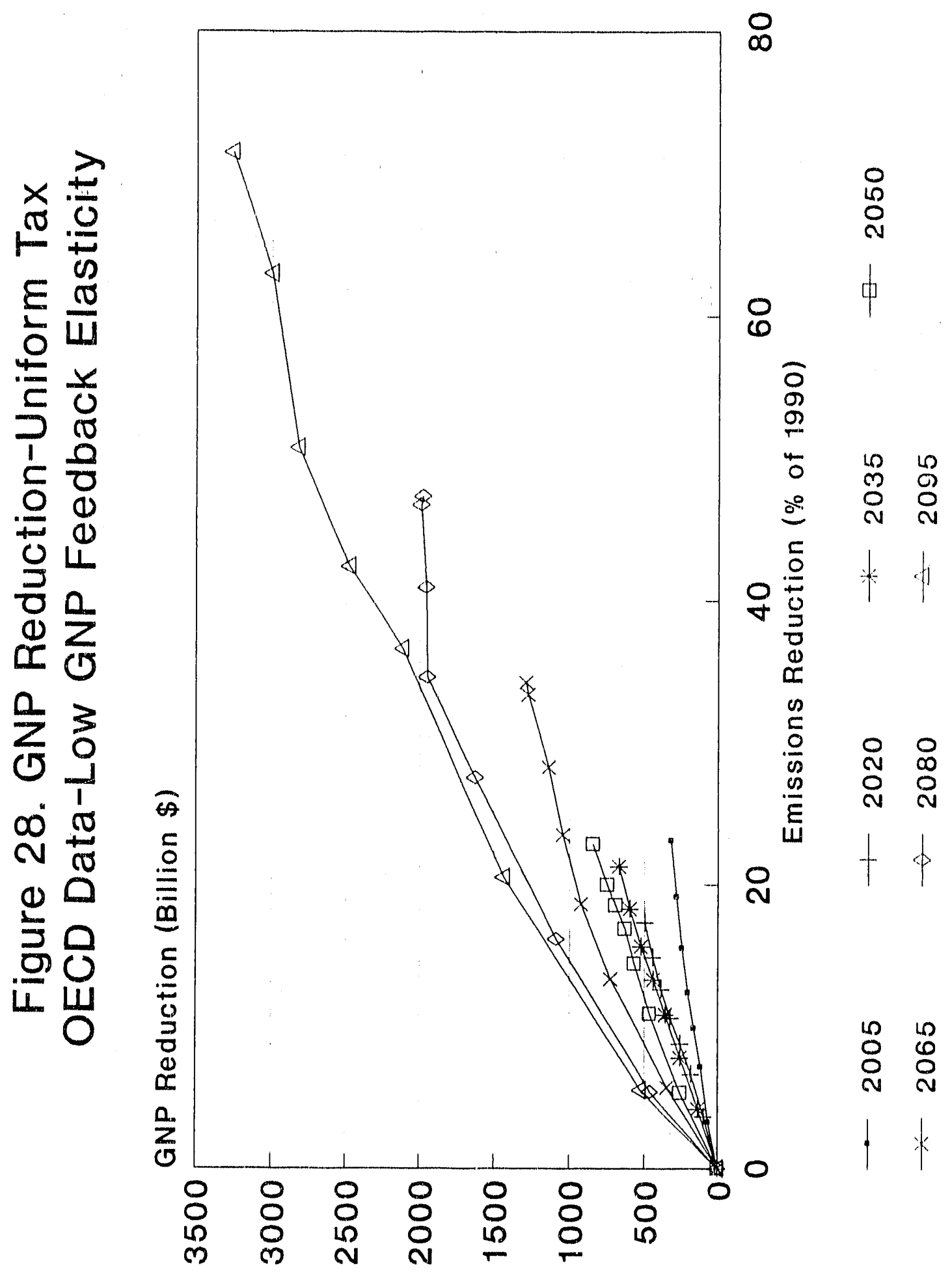

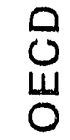


DATE FILMED 5101192 


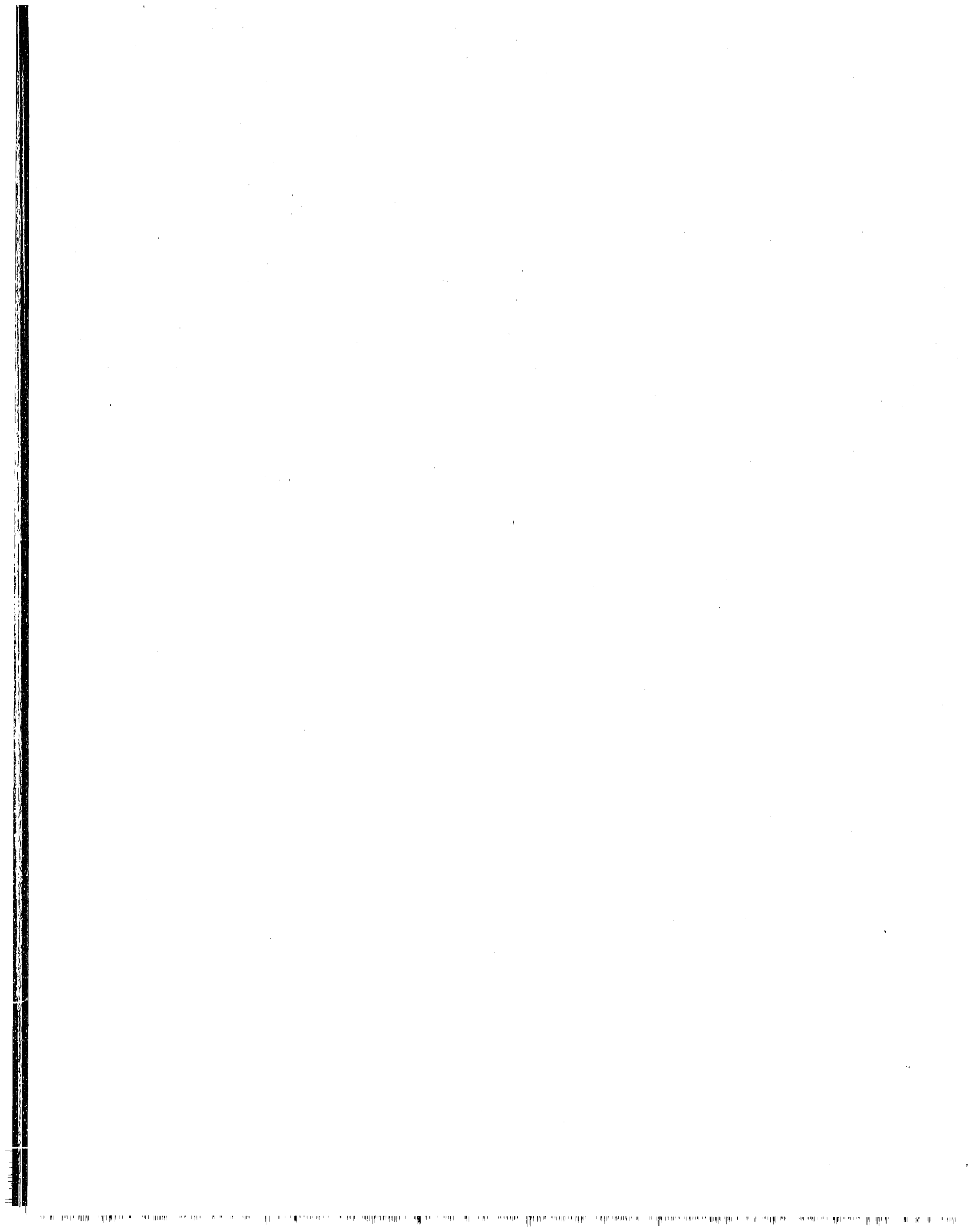

